\title{
Volatile (S, Cl and F) and fluid mobile trace element compositions in melt inclusions: implications for variable fluid sources across the Kamchatka arc
}

\author{
Tatiana Churikova $\cdot$ Gerhard Wörner · \\ Nikita Mironov · Andreas Kronz
}

Received: 1 August 2006/ Accepted: 20 February 2007/Published online: 15 March 2007

(C) Springer-Verlag 2007

\begin{abstract}
Volatile element, major and trace element compositions were measured in glass inclusions in olivine from samples across the Kamchatka arc. Glasses were analyzed in reheated melt inclusions by electron microprobe for major elements, $\mathrm{S}$ and $\mathrm{Cl}$, trace elements and $\mathrm{F}$ were determined by SIMS. Volatile element-trace element ratios correlated with fluid-mobile elements $(\mathrm{B}, \mathrm{Li})$ suggesting successive changes and three distinct fluid compositions with increasing slab depth. The Eastern Volcanic arc Front (EVF) was dominated by fluid highly enriched in $\mathrm{B}, \mathrm{Cl}$ and chalcophile elements and also LILE (U, Th, Ba, $\mathrm{Pb}$ ), F, S and LREE (La, Ce). This arc-front fluid contributed less to magmas from the central volcanic zone and was not involved in back arc magmatism. The Central Kamchatka Depression (CKD) was dominated by a second fluid enriched in $\mathrm{S}$ and $\mathrm{U}$, showing the highest $\mathrm{S} / \mathrm{K}_{2} \mathrm{O}$ and $\mathrm{U} / \mathrm{Th}$ ratios. Additionally this fluid was unusually enriched in ${ }^{87} \mathrm{Sr}$ and ${ }^{18} \mathrm{O}$. In the back arc Sredinny Ridge (SR) a third
\end{abstract}

Communicated by J. Hoefs.

Electronic supplementary material The online version of this article (doi:10.1007/s00410-007-0190-z) contains supplementary material, which is available to authorized users.

T. Churikova · G. Wörner $(\bowtie) \cdot$ A. Kronz

Geochemisches Institut, Goldschmidtstr. 1,

37077 Göttingen, Germany

e-mail: gwoerne@gwdg.de

T. Churikova

Institute of Volcanic Geology and Geochemistry,

Piip Avenue 9, Petropavlovsk-Kamchatsky, Russia

N. Mironov

Vernadsky Institute of Geochemistry and Analytical Chemistry,

Kosygin Str, 19, 117975 Moscow, Russia fluid was observed, highly enriched in $\mathrm{F}, \mathrm{Li}$, and $\mathrm{Be}$ as well as LILE and LREE. We argue from the decoupling of B and $\mathrm{Li}$ that dehydration of different water-rich minerals at different depths explains the presence of different fluids across the Kamchatka arc. In the arc front, fluids were derived from amphibole and serpentine dehydration and probably were water-rich, low in silica and high in B, LILE, sulfur and chlorine. Large amounts of water produced high degrees of melting below the EVF and CKD. Fluids below the CKD were released at a depth between 100 and $200 \mathrm{~km}$ due to dehydration of lawsonite and phengite and probably were poorer in water and richer in silica. Fluids released at high pressure conditions below the back arc (SR) probably were much denser and dissolved significant amounts of silicate minerals, and potentially carried high amounts of LILE and HFSE.

Keywords Melt inclusions - Kamchatka · fluids . Trace elements $\cdot$ Arc magmatism

\section{Introduction}

Volatile elements such as $\mathrm{S}, \mathrm{Cl}$ and $\mathrm{F}$ have significant influence on magma evolution but their behavior in subduction settings is still poorly understood. It has been shown that $\mathrm{Cl}$ and $\mathrm{F}$ are important species in subducted fluids (e.g. Alt et al. 1993; Metrich et al. 1999; Portnyagin et al. 2002) and that sulfur dioxide is one of the three most abundant volatiles in volcanic gases after $\mathrm{H}_{2} \mathrm{O}$ and $\mathrm{CO}_{2}$ (e.g., Carrol and Webster 1994). Because of the high fluid mobility of sulfur and chlorine-less so for fluorine-the mantle wedge in subduction settings becomes enriched in those elements by subduction fluids released from the subducted altered oceanic crust and its sediment. 
Fluid-mobile elements such as $\mathrm{B}, \mathrm{Li}$, and cosmogenic ${ }^{10} \mathrm{Be}$ have been found as enriched species in many volcanic arc lavas due to the input from the subducted slab (e.g., Chan et al. 1999; Ishikawa et al. 2001). It has been shown (Brenan et al. 1998a; Ryan and Langmuir 1987) that these three elements are not highly fractionated from each other during melting and crystallization, but their mineral-fluid partitioning (Brenan et al. 1998b) suggests distinct "fluid release" patterns and decoupling of fluids with changing $P-T$ conditions during subduction. However, $\mathrm{B}, \mathrm{Li}$, and ${ }^{10} \mathrm{Be}$ often show positive correlation and continuously decrease from the front to back arcs (Moriguti and Nakamura 1998; Chan et al. 1999; Ishikawa et al. 2001). The details of how volatiles are transferred into the upper mantle and what the systematic changes are in fluid chemistry with increased slab depth remain largely unresolved.

Because the volatile elements in whole rocks are strongly affected by degassing before and during eruption (Hansteen and Gurenko 1998; Metrich et al. 1999; Edmonds et al. 2001; de Moor et al. 2005; Wallace 2005), melt inclusions trapped in pristine igneous minerals are potentially the best data source to study initial volatile contents in primary and parental melts (Danyushevsky et al. 2002). Melt inclusions also provide an opportunity to extend the data on melt compositions beyond the range covered by whole rocks towards more primitive compositions (Sobolev et al. 2000). The combination of electron microprobe and SIMS analyses on glass inclusions also provides a great advantage since variable trace element patterns can be directly related to variable fluid signatures and thus constrain different fluids and their capacity to carry certain trace elements.

\section{Geological setting and geochemical signatures of arc rocks in Kamchatka}

The Kamchatka Peninsula forms the northern part of the Kurile-Kamchatka volcanic arc. It is located at the NE convergent boundary of the Eurasian and Pacific plates. Shiveluch volcano, located near the Aleutian-Kamchatka triple-junction (Yogodzinski et al. 2001), forms the northern boundary of Kamchatka's volcanic activity. From the east, the Pacific plate, carrying the $65 \mathrm{Ma}$ old Emperor Seamount chain, is being subducted below Kamchatka at the rate of $\sim 9 \mathrm{~cm} / \mathrm{a}$ (Geist and Scholl 1994). Active volcanism continues southwards to the Kurile Island arc.

From east to west, arc volcanism on Kamchatka comprises three zones parallel to the subduction trench (Fig. 1): (1) the Eastern Volcanic Front (EVF), 2) the Central Kamchatka Depression with the large Kluchevskaya Group (CKD) and three more northern volcanoes (NCKD) and (3) Sredinny Ridge (SR) of the back arc. The slab depth increases from 90 to $110 \mathrm{~km}$ below the EVF to $180-200 \mathrm{~km}$
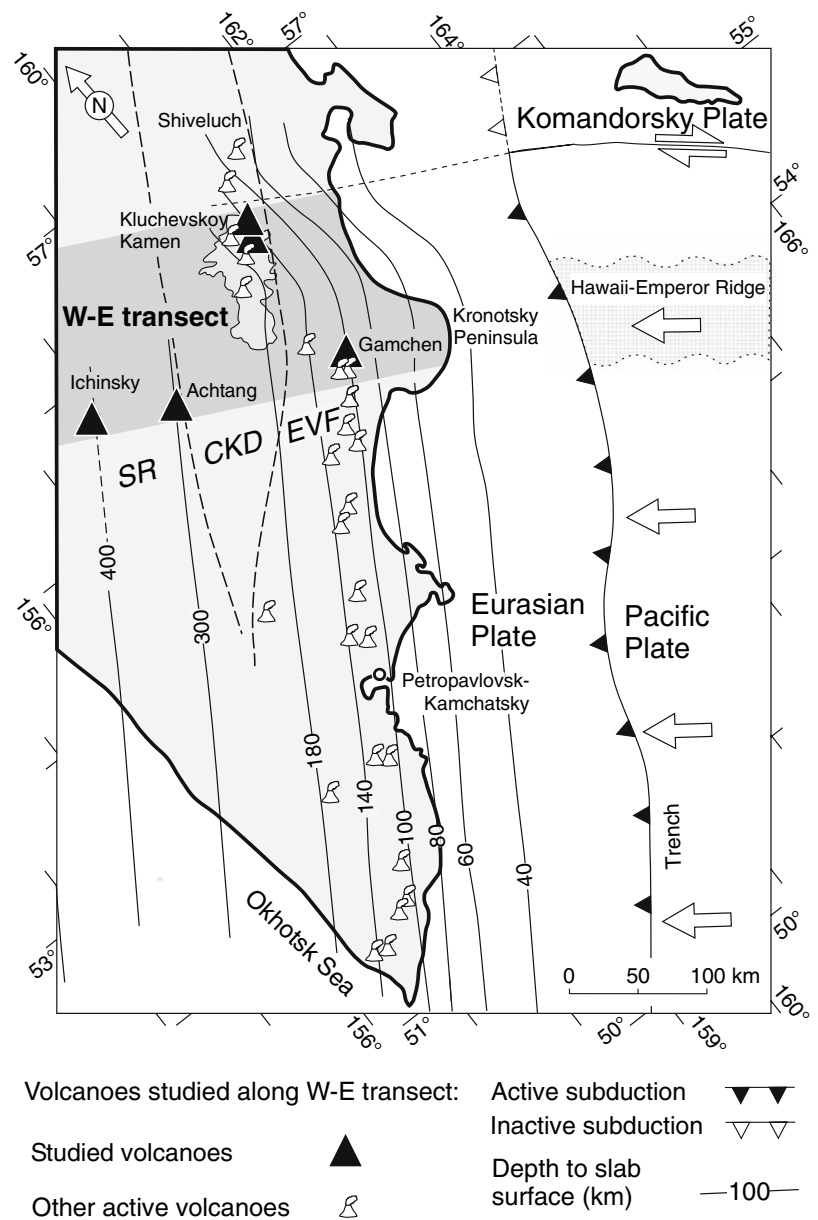

Fig. 1 Plate tectonic setting of the Kamchatka arc and location of the transect in N-Kamchatka (shaded zone). The depth to Benioff zone is from (Gorbatov et al. 1997). Studied volcanoes are marked by shaded symbols. CKD borders are from Masurenkov (1991)

below the CKD and 300-400 km below the SR (Gorbatov et al. 1997).

Interest for Kamchatka stems in particular from the large magma production rate, abundance of Recent and historical eruptions, mafic composition of the lavas and limited sedimentary component in their source compared with other arcs (Kersting and Arculus 1995; Turner et al. 1998; Churikova et al. 2001). This offers the chance to investigate a relatively simple system. Moreover, the across-arc distance over which Holocene volcanic activity and large stratovolcanos occurs (about $220 \mathrm{~km}$ ) is comparably large on Kamchatka and possibly the largest in the world. Moreover the Kamchatka is one of the most active volcanic areas of the Northern Hemisphere and produced many large Plinian eruptions during the Holocene. Due to high elevation of the volcanoes (e.g., Kluchevskoy volcano; $4,750 \mathrm{~m}$ ) many of the eruptions reach the stratosphere and may thus result in significant input of volatiles to the upper atmosphere. 
Dorendorf et al. (2000a) and Churikova et al. (2001) described the geochemical features of the rocks from a $220 \mathrm{~km}$ E-W transect across Kamchatka's volcanic zones (Fig. 1). They sampled mafic lavas $(>5 \% \mathrm{MgO})$ of Upper Pleistocene and Holocene age from stratovolcanoes and monogenetic cones in three volcanically active areas. They found that the rocks were medium to high K-calkalkaline with typical but variable arc-like trace element signatures. Systematic geochemical variations in major and trace elements from the volcanic front to the back arc exist (Fig. 2a): $\mathrm{K}$ and most incompatible trace elements, i.e., HFSE, LILE, LREE, and certain element ratios $(\mathrm{K} / \mathrm{Na}, \mathrm{La} / \mathrm{Yb}, \mathrm{Ce} / \mathrm{Yb}$, $\mathrm{Sr} / \mathrm{Y}, \mathrm{Nb} / \mathrm{Yb}$ ) increased with slab depth from the arc front (EVF) to back arc (SR). HREE abundances were unfractionated and lower than in NMORB by a factor of 1.3-1.9.

The transect results suggest that the Kamchatka mantle wedge is variably depleted possibly due to earlier MORBor intra-arc rifting and melting events (Churikova et al. 2001). HFSE and Hf isotope systematics (Münker et al. 2004) show that EVF and CKD magmas formed from a depleted mantle source with low $\mathrm{Ta} / \mathrm{Yb}$ ratios. By contrast, lavas from the SR back arc have a significant contribution of a source relatively rich in HFSE (higher $\mathrm{Ta} / \mathrm{Yb}$, low $\mathrm{Zr} /$ $\mathrm{Nb}$ and $\mathrm{Ba} / \mathrm{Nb}$ ratios). Based on the amount of an OIB component in the mantle source, Churikova et al. (2001) distinguish two groups of back arc rocks: (I) back arc basalts (IAB), which are only slightly (up to 5\%) enriched by an OIB-type mantle component in their source and (II) within-plate types basalts (WPT) with a minor slab fluid signature. Group II is enriched by an OIB component in their source up to $35 \%$.

Forsteritic olivines in CKD rocks show enrichment compared to MORB in ${ }^{18} \mathrm{O}$-isotopes (up to $7.5 \%$ ) while their hosts are only slightly enriched in ${ }^{87} \mathrm{Sr} /{ }^{86} \mathrm{Sr}(0.70366)$ at nearly constant Nd-isotopes. Dorendorf et al. (2000a) attribute this observation to a relatively large fluid flux from the subducted Emperor Seamount chain.

These studies indicate that several components appear to be involved in magma generation below Kamchatka: a depleted MORB source, an OIB component (in SR rocks) and variably enriched in ${ }^{18} \mathrm{O}$ and ${ }^{87} \mathrm{Sr} /{ }^{86} \mathrm{Sr}$-isotopes (EVF, CKD) slab fluids. The data of Dorendorf et al (2000a, b) and Churikova et al (2001) show that $\mathrm{Pb}$ isotopic variations do not correlate with any slab fluid parameters (e.g., ${ }^{87} \mathrm{Sr} /{ }^{86} \mathrm{Sr}$, fluid mobile elements). This suggests that terrigenous or pelagic sediments do not contribute in any significant way to these magmas, and fluids are clearly dominated by devolatilization of the subducted oceanic crust and rocks of the Emperor Seamount Chain.

In this paper, we characterize the volatiles across this highly productive arc, document the nature of these fluids and quantify their release patterns during subduction. Our study on volatiles in basaltic melts from Kamchatka aims at
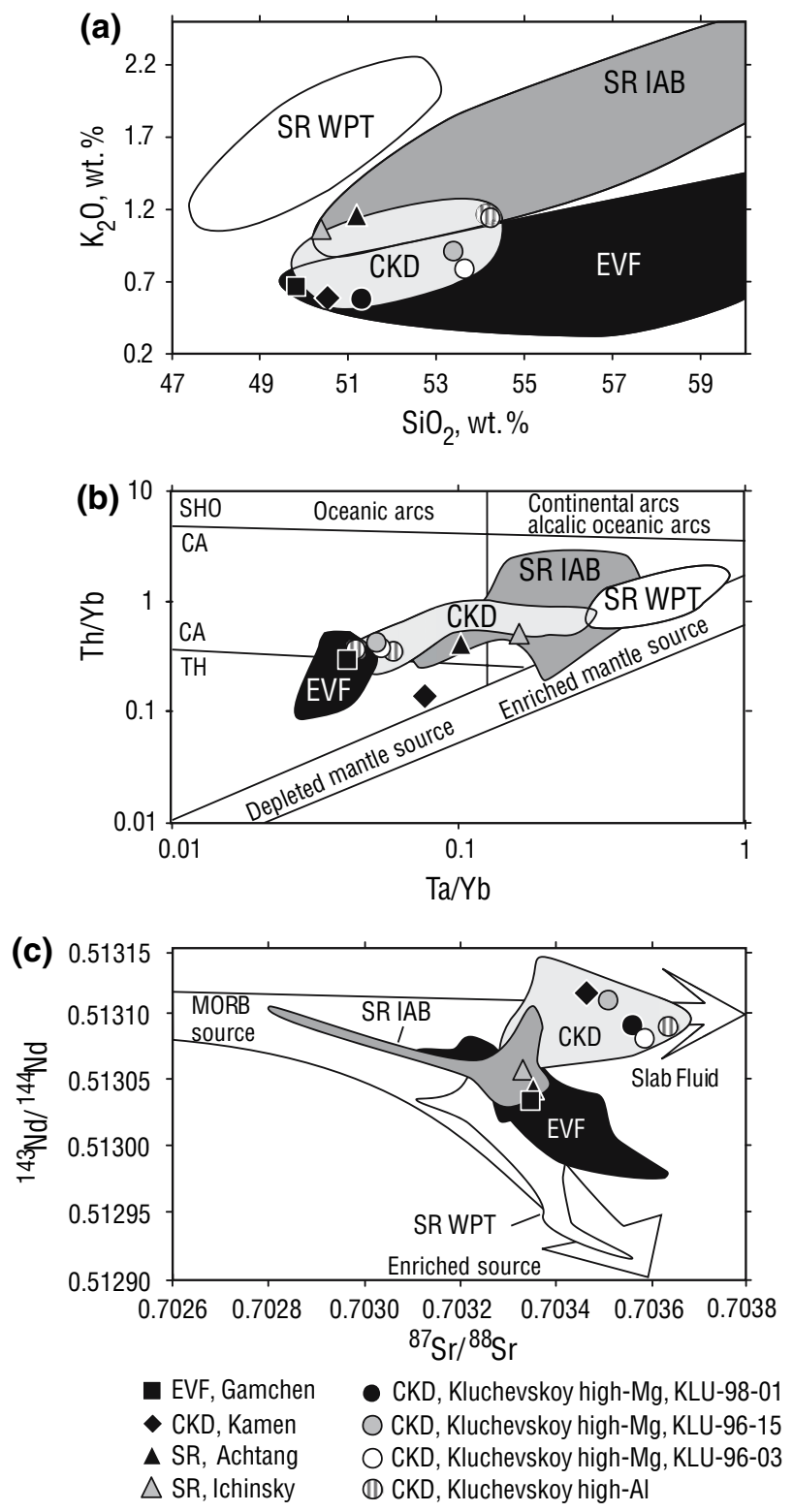

Fig. 2 Representative compositional features of the lavas selected for the melt inclusion study. The fields of additional whole rock data from each zone are shown for comparison (data from Churikova et al. 2001). The most magnesian samples are chosen from each volcanic zone: a for a given $\mathrm{SiO}_{2}$ potassium increases from the arc front to back arc; b demonstrates depleted and enriched mantle sources for Kamchatka arc rocks; c CKD magmas are relatively enriched in ${ }^{87} \mathrm{Sr} /{ }^{88} \mathrm{Sr}$ at constant $\mathrm{Nd}$ isotopes; SR samples lie on the mantle array from MORB to OIB sources

understanding slab devolatilization along a $220 \mathrm{~km}$ transect across this active arc by analyzing glass inclusions.

\section{Samples and analytical methods}

Nine representative basalt samples were selected from each part of the transect. Volatile $(\mathrm{S}, \mathrm{Cl}, \mathrm{F})$, major and trace elements were measured in reheated melt inclusions (melt 
inclusions) hosted in olivines ( $\mathrm{FO}_{78-92}$ ) of lava samples from Gamchen (EVF), Kluchevskoy and Kamen (CKD) and Achtang and Ichinsky (SR) (Figs. 1, 2; Table 1). In the present paper we focused on samples from Group I of the SR (Fig. 2a-c). Most of our samples were from monogenetic cinder cones and had $\mathrm{Mg} \#$ from 51.5 to 70.7. Their mafic character suggested relatively limited and short melt evolution before eruption.

Figure $2 \mathrm{a}-\mathrm{c}$ shows the principal compositional features of the samples studied in this paper. The fields of additional whole rock analyses from Churikova et al. (2001) for each zone are shown for comparison. Potassium enrichment at a given $\mathrm{SiO}_{2}$ or $\mathrm{MgO}$ content is observed from the arc front to back arc and samples were chosen for the melt inclusion study to represent these variations (Fig. 2a). The Ta/Yb versus $\mathrm{Th} / \mathrm{Yb}$ diagram demonstrates that $\mathrm{EVF}$ and $\mathrm{CKD}$ samples have a depleted mantle source even compared to NMORB and the rocks from SR have a variable addition of an enriched OIB-like source component. Our melt inclusion data mimic the arc front to back arc compositional variations documented for whole rocks. Figure $2 \mathrm{c}$ highlights $\mathrm{Sr}-\mathrm{Nd}$ isotopic data for those whole rock samples studied here. The rocks from the CKD are relatively enriched in ${ }^{87} \mathrm{Sr} /{ }^{88} \mathrm{Sr}$ at constant $\mathrm{Nd}$ isotopes, which supports Dorendorf et al. (2000a) notion of a particularly large fluid flux. SR samples, by contrast, lie on the mantle array typical for MORB to OIB sources. Thus, our samples represent the entire compositional and spatial variation across Kamchatkas most productive arc sections.

Melt inclusions from these samples were found in $\mathrm{Ol}$ and Cpx phenocrysts and had typical sizes from 10 to $100 \mu \mathrm{m}$. The majority of these inclusions were partially crystallized with $\mathrm{Ol}, \mathrm{Opx}, \mathrm{Cpx}, \mathrm{Pl}, \mathrm{Sp}, \mathrm{Mt}$, and had shrinkage bubbles. No volatile-bearing minerals (except sulfides, which is considered in detail later) were found in the inclusions as daughter phases.
To study the initial volatile composition early in the evolution of the melts, we focused this study to melt inclusions in the most magnesian olivine phenocrysts. These glasses were found for example in olivines from high-Mg lavas of Kluchevskoy volcano (CDK) with $\mathrm{MgO}>9$ wt. $\%$ and $\mathrm{CaO}>11$ wt.\%, representing primary, undegassed melts. The samples of Achtang (SR, olivine $\mathrm{Fo}_{82-86}$ and $\mathrm{MgO} \sim 5.5-8 \mathrm{wt} \%$ in melt inclusions), and Gamchen (EVF, olivine $\mathrm{Fo}_{84-86}$ and $\mathrm{MgO} \sim 7.8-9$ wt. $\%$ in melt inclusions) volcanoes were more evolved. The most evolved inclusions were studied from Kamen volcano (CDK) and Ichinsky dike basalt (SR) with olivine $\mathrm{Fo}_{79-81}$ and inclusions with $\mathrm{MgO} \sim 4.5-6 \mathrm{wt} \%$. Thus, fractional crystallization had modified the initial fluid signature of these included melts to some extend. In addition, postentrapment degassing (as discussed in detail later) also affected volatile contents.

To avoid the effect of crystallization within melt inclusions and to assess the major and trace element composition of the initially trapped melts, 133 inclusions were reheated, melted and partially homogenized (Danyushevsky et al. 2002) and then analyzed by electron microprobe for major elements, sulfur and chlorine. A subset of 60 reheated inclusions was analyzed by ion probe for trace elements and fluorine.

Analytical data for representative reheated melt inclusions are presented in Table 2, a full data set can be found in the data repository (electronic supplement eTable 1,2) or from the first two authors upon request. The number of reheated melt inclusions per sample varied from 4 to 35. During the reheating experiment most daughter silicate and oxide phases were dissolved, only some remnants of pyroxene and spinel were observed in a few inclusions. Shrinkage bubbles and daughter sulfides decreased in size but were not removed completely after heating (Fig. 3).

Table 1 Main characteristics of the samples used in melt inclusion study

\begin{tabular}{|c|c|c|c|c|c|c|c|c|c|c|}
\hline No. & Sample & Region & Volcano & Lithology & Age & $\mathrm{SiO}_{2}$ & $\mathrm{MgO}$ & $\mathrm{Mg} \#$ & $\mathrm{Fo}_{\mathrm{s}}^{\mathrm{a}}$ & $\mathrm{Fo}_{\mathrm{h}}^{\mathrm{b}}$ \\
\hline 1 & GAM-96-28 & Eastern Volcanic Front (EVF) & Gamchen & Basalt & $\mathrm{Q}_{2} ?$ & 49.8 & 6.24 & 52.0 & $60-90$ & $84-86$ \\
\hline 2 & KLU-98-01 & Central Kamchatka Depression (CKD) & Kluchevskoy & Mg-basalt & $\mathrm{Q}_{4}$ & 51.94 & 11.72 & 70.7 & $73-91$ & $86.5-92$ \\
\hline 3 & KLU-96-03 & & Kluchevskoy & Mg-basalt & $\mathrm{Q}_{4}$ & 53.70 & 8.88 & 65.7 & $73-92$ & $83-91$ \\
\hline 4 & KLU-96-15 & & Kluchevskoy & Mg-basalt & $\mathrm{Q}_{4}$ & 53.70 & 7.32 & 61.2 & $80-92$ & $84-89$ \\
\hline 5 & KLU-96-02 & & Kluchevskoy & Al-basalt & $\mathrm{Q}_{4}$ & 53.99 & 5.19 & 52.7 & $67-91$ & $80-84.5$ \\
\hline 6 & KLU-96-14 & & Kluchevskoy & Al-basalt & $\mathrm{Q}_{1}$ & 54.44 & 4.95 & 51.5 & $72-84$ & 83 \\
\hline 7 & 2310 & & Kamen & Mg-basalt & $\mathrm{Q}_{3}$ & 50.54 & 7.13 & 57.1 & $66-82.5$ & $78-81$ \\
\hline 8 & ICH-96-19 & Sredinny Ridge (SR) & Ichinsky & Basalt & $\mathrm{Q}_{4} ?$ & 50.40 & 4.88 & 52.5 & $70-84$ & $79-80.5$ \\
\hline 9 & ACH-96-02 & & Achtang & Mg-basalt & $\mathrm{Q}_{4} ?$ & 51.20 & 7.89 & 62.4 & $79-87.5$ & $82-86.5$ \\
\hline
\end{tabular}

a Range of the olivine compositions in each basalt

b Olivine compositions for grains used in heating experiment 
Table 2 Major, trace and volatile element contents in a representative set of the reheated melt inclusion glasses, recalculated to equilibrium with their host olivine

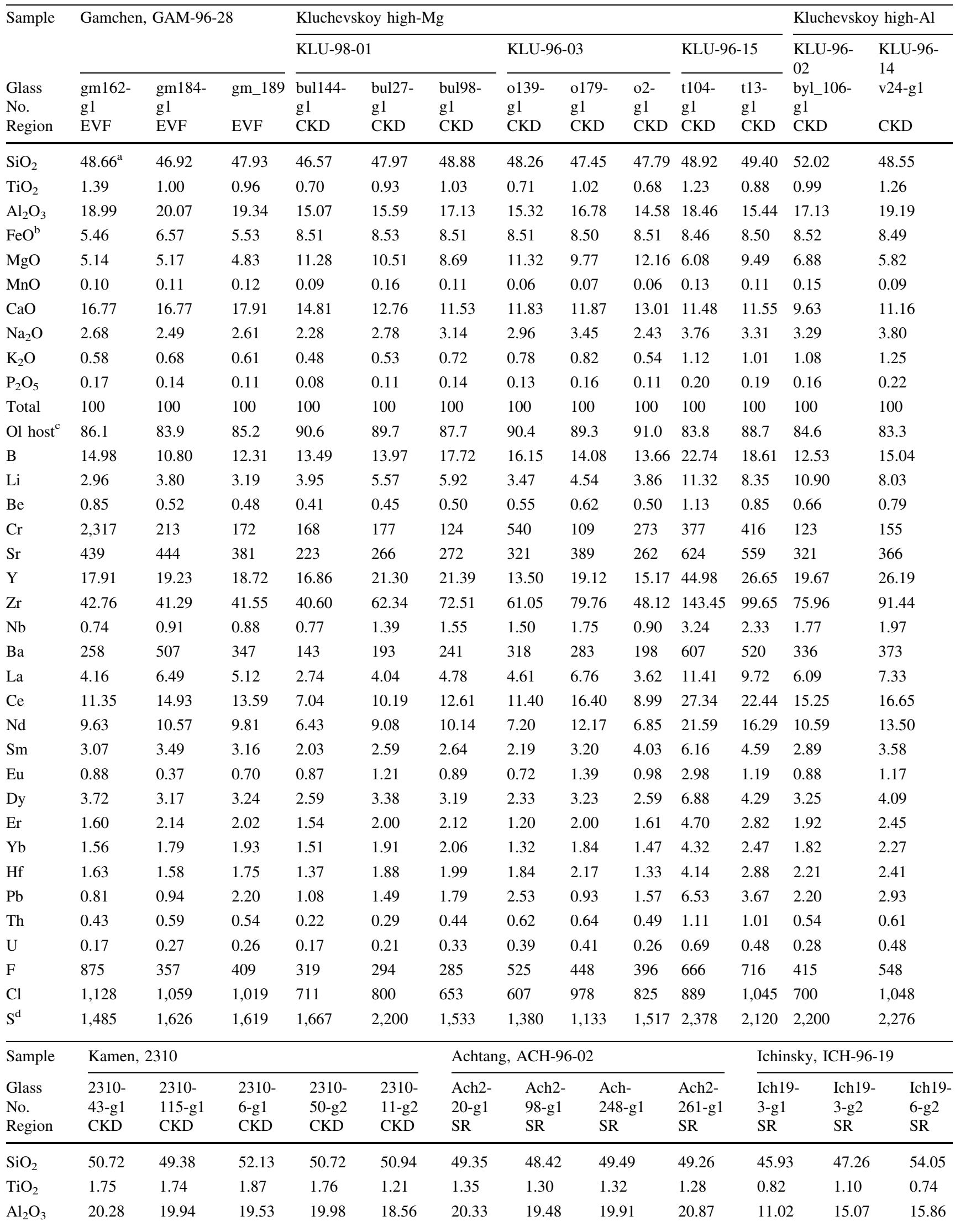


Table 2 continued

\begin{tabular}{|c|c|c|c|c|c|c|c|c|c|c|c|c|}
\hline \multirow{2}{*}{$\begin{array}{l}\text { Sample } \\
\text { Glass } \\
\text { No. } \\
\text { Region }\end{array}$} & \multicolumn{5}{|c|}{ Kamen, 2310} & \multicolumn{4}{|c|}{ Achtang, ACH-96-02 } & \multicolumn{3}{|c|}{ Ichinsky, ICH-96-19 } \\
\hline & $\begin{array}{l}2310- \\
43-g 1 \\
\text { CKD }\end{array}$ & $\begin{array}{l}2310- \\
115-\mathrm{g} 1 \\
\text { CKD }\end{array}$ & $\begin{array}{l}2310- \\
6-g 1 \\
\text { CKD }\end{array}$ & $\begin{array}{l}2310- \\
50-\mathrm{g} 2 \\
\text { CKD }\end{array}$ & $\begin{array}{l}2310- \\
11-g 2 \\
\text { CKD }\end{array}$ & $\begin{array}{l}\text { Ach2- } \\
20-g 1 \\
\text { SR }\end{array}$ & $\begin{array}{l}\text { Ach2- } \\
\text { 98-g1 } \\
\text { SR }\end{array}$ & $\begin{array}{l}\text { Ach- } \\
248-g 1 \\
\text { SR }\end{array}$ & $\begin{array}{l}\text { Ach2- } \\
\text { 261-g1 } \\
\text { SR }\end{array}$ & $\begin{array}{l}\text { Ich19- } \\
\text { 3-g1 } \\
\text { SR }\end{array}$ & $\begin{array}{l}\text { Ich19- } \\
3-g 2 \\
\text { SR }\end{array}$ & $\begin{array}{l}\text { Ich19- } \\
6-g 2 \\
\text { SR }\end{array}$ \\
\hline $\mathrm{FeO}$ & 6.33 & 6.52 & 7.01 & 6.55 & 7.03 & 6.22 & 6.60 & 6.24 & 5.94 & 15.06 & 10.76 & 9.85 \\
\hline $\mathrm{MgO}$ & 3.89 & 3.70 & 3.82 & 3.63 & 3.95 & 4.08 & 6.15 & 5.57 & 5.07 & 8.43 & 6.19 & 6.31 \\
\hline $\mathrm{MnO}$ & 0.15 & 0.14 & 0.16 & 0.14 & 0.15 & 0.12 & 0.14 & 0.12 & 0.12 & 0.12 & 0.19 & 0.17 \\
\hline $\mathrm{CaO}$ & 10.46 & 12.80 & 8.91 & 11.13 & 12.18 & 12.05 & 12.77 & 11.92 & 11.78 & 14.43 & 14.68 & 7.86 \\
\hline $\mathrm{Na}_{2} \mathrm{O}$ & 5.05 & 4.52 & 5.03 & 4.70 & 4.59 & 4.42 & 3.42 & 3.57 & 3.74 & 2.84 & 3.29 & 3.68 \\
\hline $\mathrm{K}_{2} \mathrm{O}$ & 1.00 & 0.93 & 1.15 & 0.99 & 1.03 & 1.57 & 1.25 & 1.45 & 1.44 & 0.86 & 1.05 & 1.10 \\
\hline $\mathrm{P}_{2} \mathrm{O}_{5}$ & 0.31 & 0.25 & 0.29 & 0.32 & 0.27 & 0.42 & 0.39 & 0.34 & 0.43 & 0.25 & 0.27 & 0.27 \\
\hline Total & 100 & 100 & 100 & 100 & 100 & 100 & 100 & 100 & 100 & 100 & 100 & 100 \\
\hline Ol host & 81.2 & 79.6 & 79.2 & 79.1 & 79.1 & 82.1 & 86.5 & 85.9 & 85.3 & 79.7 & 80.0 & 80.0 \\
\hline B & 14.07 & 11.95 & 14.05 & 15.90 & 12.34 & 7.66 & 5.22 & 5.78 & 6.24 & 2.86 & 3.11 & 4.38 \\
\hline $\mathrm{Li}$ & 7.11 & 5.15 & 5.50 & 9.31 & 5.91 & 11.58 & 6.64 & 7.02 & 8.44 & 13.11 & 11.66 & 9.27 \\
\hline $\mathrm{Be}$ & 1.04 & 0.74 & 0.99 & 0.99 & 0.65 & 1.14 & 1.01 & 1.15 & 0.98 & 1.20 & 1.30 & 3.67 \\
\hline $\mathrm{Cr}$ & 426 & 157 & 298 & 687 & 172 & 166 & 256 & 280 & 883 & 2,388 & 1,236 & 2,111 \\
\hline $\mathrm{Sr}$ & 372 & 399 & 422 & 428 & 361 & 762 & 555 & 541 & 678 & 616 & 584 & 590 \\
\hline $\mathrm{Y}$ & 28.71 & 29.24 & 22.64 & 30.39 & 21.50 & 23.53 & 22.18 & 19.65 & 21.42 & 18.04 & 16.84 & 15.12 \\
\hline $\mathrm{Zr}$ & 90.91 & 87.20 & 99.15 & 97.07 & 70.60 & 118.01 & 99.33 & 96.01 & 112.52 & 61.28 & 61.30 & 84.05 \\
\hline $\mathrm{Nb}$ & 2.16 & 2.27 & 2.36 & 2.51 & 2.15 & 6.96 & 4.73 & 5.25 & 5.79 & 3.31 & 2.71 & 3.66 \\
\hline $\mathrm{Ba}$ & 268 & 220 & 293 & 282 & 218 & 536 & 368 & 391 & 467 & 475 & 444 & 391 \\
\hline $\mathrm{La}$ & 5.83 & 5.69 & 6.29 & 7.09 & 5.35 & 13.34 & 10.33 & 9.75 & 11.57 & 7.31 & 6.99 & 8.03 \\
\hline $\mathrm{Ce}$ & 16.86 & 16.95 & 18.53 & 18.76 & 14.56 & 34.79 & 25.79 & 23.84 & 30.11 & 18.64 & 17.91 & 20.34 \\
\hline $\mathrm{Nd}$ & 13.75 & 13.42 & 14.64 & 15.35 & 10.44 & 19.66 & 16.56 & 14.51 & 16.73 & 14.03 & 13.56 & 12.62 \\
\hline $\mathrm{Sm}$ & 4.56 & 4.43 & 4.57 & 7.76 & 3.31 & 4.85 & 4.72 & 3.58 & 4.46 & 3.77 & 3.39 & 3.65 \\
\hline $\mathrm{Eu}$ & 1.35 & 1.49 & 1.29 & 1.90 & 1.22 & 0.97 & 1.35 & 1.02 & 1.85 & 1.18 & 1.37 & 0.86 \\
\hline Dy & 5.21 & 5.02 & 4.53 & 6.05 & 3.71 & 4.08 & 3.78 & 3.32 & 3.69 & 3.65 & 3.18 & 2.95 \\
\hline Er & 3.12 & 3.09 & 2.22 & 3.46 & 2.09 & 2.37 & 2.33 & 2.02 & 2.27 & 1.98 & 1.72 & 1.62 \\
\hline $\mathrm{Yb}$ & 2.46 & 2.80 & 1.78 & 2.30 & 2.43 & 2.28 & 2.17 & 1.85 & 2.10 & 1.65 & 1.49 & 1.24 \\
\hline $\mathrm{Hf}$ & 2.84 & 2.68 & 3.10 & 4.05 & 1.94 & 3.18 & 2.79 & 2.36 & 2.88 & 2.06 & 1.97 & 2.18 \\
\hline $\mathrm{Pb}$ & 17.16 & 1.06 & 1.67 & 2.37 & 2.94 & 5.09 & 3.50 & 2.78 & 4.81 & & 3.75 & 2.07 \\
\hline Th & 0.45 & 0.44 & 0.56 & 0.51 & 0.53 & 0.76 & 0.59 & 0.59 & 0.76 & 0.68 & 0.62 & 0.45 \\
\hline $\mathrm{U}$ & 0.28 & 0.28 & 0.46 & 0.61 & 0.33 & 0.58 & 0.37 & 0.39 & 0.47 & 0.28 & 0.31 & 0.25 \\
\hline $\mathrm{F}$ & 1,001 & 726 & 1,204 & 1,061 & 600 & 1,077 & 411 & 555 & 824 & 886 & 773 & 1,231 \\
\hline $\mathrm{Cl}$ & 1,196 & 1,207 & 1,237 & 1,131 & 1,171 & 548 & 384 & 503 & 494 & 405 & 540 & 288 \\
\hline $\mathrm{S}$ & 1,571 & 1,793 & 1,620 & 1,806 & 1,665 & 1,552 & 1,662 & 1,250 & 1,423 & 894 & 867 & 1,308 \\
\hline
\end{tabular}

${ }^{a}$ Major elements are given in weight percent. trace elements in ppm

b Total iron expressed as $\mathrm{FeO}$

c Mg\# of host olivine

${ }^{\mathrm{d}}$ Sulfur data are recalculated values for incomplete sulfide dissolution after heating using a combination of glass analyses and back-calculation of sulfide globule contents

Homogenization of melt inclusions

Selected olivine grains with partially crystallized melt inclusions (30-100 $\mu \mathrm{m}$ in size) were doubly polished and heated in Vernadsky Institute of Geochemistry (Russia) following the technique of Sobolev and Danyushevsky (1994). Olivine sections 1-2 mm thick, were mounted in a high-temperature (up to $1,600^{\circ} \mathrm{C}$ ) low-inertia heating stage (Sobolev and Slutsky 1984). Experiments have been carried out under visual control in ultra-pure helium additionally purified with a high-temperature zirconium filter. The temperature of the experiments was measured with a $\mathrm{Pt}-\mathrm{Pt}_{90} \mathrm{Rh}_{10}$ thermocouple and calibrated against the melting point of $\mathrm{Au}\left(1,063^{\circ} \mathrm{C}\right)$. To avoid volatile loss, the 
Fig. 3 Back-scattered images of reheated melt inclusions (a-e) and sulfide globules (f) in Kamchatka olivines. Sulfide globules in melt inclusions did not disappear after heating experiments, but the area ratio of sulfide globules and glass in inclusions is nearly constant (about 1/10). $\mathrm{Ol}$ olivine, Sulph sulfide,

$C p x$ clinopyroxene, $S p$ spinel, $M I$ melt inclusion, $S b$ shrinkage bubble
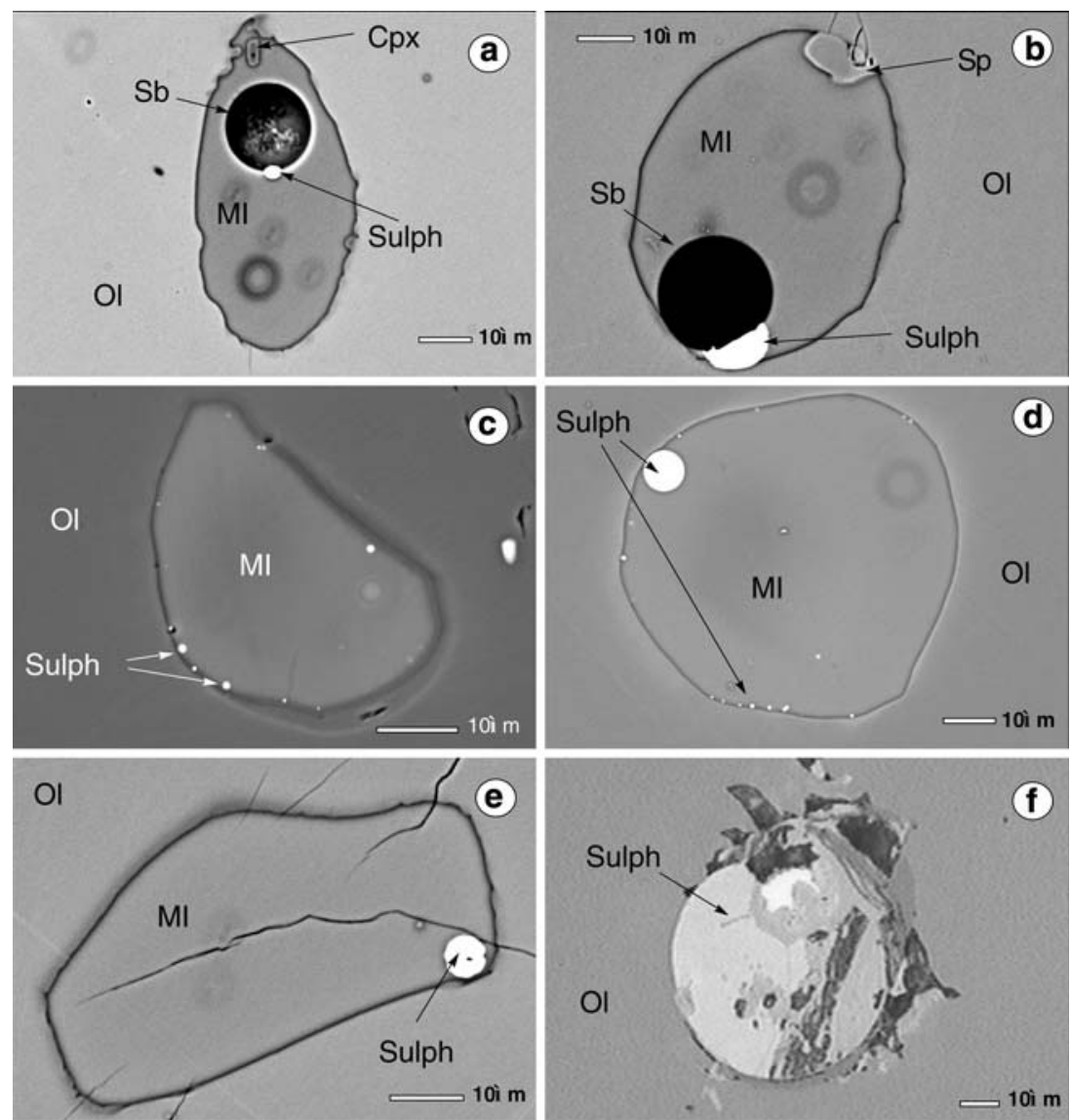

time of heating did not exceed 3-10 min. The inclusions were quenched when daughter silicate crystals were melted and the shrinkage bubbles started to move inside. After quenching, the grains were mounted in epoxy and carefully polished to expose the inclusions on the surface.

A selection of representative homogenized inclusions is shown in Fig. 3. To account for chemical changes of the included melts, all data were recalculated to melts in equilibrium with their host olivines. The recalculation was based on modeling fractional melting of olivine from the inclusion walls after Danyushevsky et al. (2002). Because of the high $\mathrm{Mg \#}$ in $\mathrm{Ol}$ from the Kluchevskoy samples the data for this volcano were recalculated accounting for $\mathrm{Fe}-$ $\mathrm{Mg}$ exchange between glasses and host olivine (Danyushevsky et al. 2000) using the model of Ford et al. (1983) for olivine-melt equilibria. The calculations were carried out for water-free conditions, a pressure of $1 \mathrm{bar}$, and an oxygen fugacity corresponding to the $\mathrm{Ni}-\mathrm{NiO}$ equilibrium. All raw data are presented in eTable 2.

Major, trace and volatile element analysis

Glass inclusions, host-minerals and sulfide globules were analyzed for major elements, $\mathrm{S}$ and $\mathrm{Cl}$ using routine pro- cedure analyses by a JEOL JXA 8900RL instrument at the GZG, Göttingen University, equipped with 5 WDS detectors, at $15 \mathrm{kV}, 15 \mathrm{nA}$, and 5-10 $\mu \mathrm{m}$ beam diameter. Peak counting times for major elements were 15-30 s, for $\mathrm{S}$ and $\mathrm{Cl} 60 \mathrm{~s}$. For standardization, we used a set of synthetical and natural standards.

To ensure accuracy and precision, we used a San-Carlos olivine standard (USNM 111312/444) and natural glass VG-2 (Jarosewich et al. 1980). Deviation from recommended values was less than $5 \%$. The quality of analyses was also controlled by mineral stoichiometry for the olivines. The precision of analyses for most major elements was better than 5 and $7 \%$ for $\mathrm{K}$ and $\mathrm{P}$.

From repeated measurements of a set of glass standards the precision of analyses was calculated at $\pm 5 \%$ for $\mathrm{S}$ and $\pm 1-2 \%$ for $\mathrm{Cl}$ at more than 3,000 ppm. Chlorine precision is $\pm 14 \%$ at $300 \mathrm{ppm}$ (see Table 2; electronic supplement eTable 3). The deviation from recommended values was always less than $5 \%$ for $\mathrm{S}$ and about $10 \%$ for $\mathrm{Cl}$ (eTable 3).

Ion probe analyses of trace elements, water and fluorine were carried out on the Cameca IMS-4f ion microprobe operated at the Institute of Microelectronics and Informatics RAS, Yaroslavl. The measurement procedures for trace elements and $\mathrm{H}_{2} \mathrm{O}$ analysis were similar to those 
described in detail in Smirnov et al. (1995) and Nosova et al. (2002). The method of ion probing of fluorine has been published recently in Portnyagin et al. (2002).

Samples were coated with a $20 \mathrm{~nm}$ thick gold film to avoid charge build up. $\mathrm{O}^{2-}$ primary ions were accelerated through a nominal potential of $10 \mathrm{kV}$ while a $4.5 \mathrm{kV}$ secondary accelerating voltage was applied to the sample. A primary beam current of 2-4 nA was focused on the sample over a spot diameter of 10-20 $\mu \mathrm{m}$. Secondary ions were collected from the imaged field of 10 or $25 \mu \mathrm{m}$ in diameter depending on the size of inclusions analyzed. Energy filtering of secondary ions was applied by using a sample-offset voltage of $-100 \mathrm{~V}$ and an energy window of $50 \mathrm{eV}$.

Secondary mass resolving power was kept as high as $M /$ $d M=500$ to eliminate ${ }^{9} \mathrm{Be}^{27} \mathrm{Al}^{3+}$ interference. All species in the wide mass range from ${ }^{7} \mathrm{Li}$ up to ${ }^{232} \mathrm{Th}$ were analyzed in the same measurement cycle. They were arranged evenly during increasing and descending mass scans so as to minimize mass step and therefore waiting time that was necessary to stabilize the magnetic field when switching from mass to mass.

Using the on line statistics control allowed the counting time to be variable and to correspondent to the intensity of the secondary ion current for each acquisition. Accumulation stopped when relative standard deviations did not exceed $1 \%$ for the ${ }^{30} \mathrm{Si}^{+}$reference element and $5 \%$ for other components. Maximum accumulation time was limited to $30 \mathrm{~s}$.

Volatile elements (H, F) were measured separately from trace elements and under the special conditions. At least $24 \mathrm{~h}$ pumping of the sample chamber preceded analysis of volatiles to decrease the background level. An area of $30 \times 30 \mu \mathrm{m}$ around the point to be analyzed was pre-sputtered for $3 \mathrm{~min}$ by the primary beam. A smaller $(10 \mu \mathrm{m})$ spot and a higher $(8 \mathrm{nA})$ primary ion current were applied to decrease the detection limits for $\mathrm{H}$ and $\mathrm{F}$. The samples potential was adjusted automatically prior each measurement to precisely keep the sample voltage offset.

Absolute concentrations of each element were calculated from Trace Element/ ${ }^{30} \mathrm{Si}^{+}$ratios using calibrating constants. Calibration curves were constructed using wellcertified standard samples (Jochum et al. 2000).

The stripping procedure was applied to eliminate contribution of interfering molecular oxide ions at ${ }^{153} \mathrm{Eu}^{+}$, ${ }^{174} \mathrm{Yb}^{+}$(Bottazzi et al. 1994). Quantification procedure of volatiles included subtraction of instrumental background that was determined for the host matrix (presumably characterized by negligible $\mathrm{H}$ and $\mathrm{F}$ concentrations).

The NIST 610 reference glass was used for mass scale calibration and SEM high voltage adjustment, thus ensuring reproducibility of the analytical protocol. The deviation from the value obtained during calibration for this standard did not exceed $10 \%$ for each measured component. The standard was analyzed after every 10-15 sample measurements. To ensure accuracy and precision, we used natural basaltic glass standard KL2 (Jochum et al. 2000), which was measured after every $4-5$ measurements (electronic supplement eTable 4).

\section{Sulfur measurements}

Arc magmas may contain significant amounts of $\mathrm{S}^{6+}$ relative to total S (e.g., Nilsson and Peach 1993). Due to their valency difference of eight units, the $\mathrm{K} \alpha$-lines of $\mathrm{S}^{2-}$ and $\mathrm{S}^{6+}$ display a significant energetic shift of approximately $1.3 \mathrm{eV}$ in the X-ray emission spectrum. The peak shift of the $\mathrm{S}-\mathrm{K} \alpha$ line is dominated by the valency state. Co-ordination geometry and nearest neighbors play a minor role, whereas the relative concentration of each species has no effect. Hence there is only an apparent rather than a true peak shift for a mixture of both sulfur species (Höflich et al. 2004).

To obtain information about the sulfur species, 40 reheated melt inclusions were analyzed using the peak scan-technique between covering the $S^{2+}$ and $S^{6-}$ peaks and collecting the signal in peak integrated mode. Based on the method by Carroll and Rutherford (1988) and Wallace and Carmichael (1994) four spectrometers each equipped with a PET analyzing crystal were used to obtain a wavelength scan at long counting times. The measured wavelengths ranged from 5.35604 to $5.39319 \AA$ with a step interval $0.00031 \AA$, a counting time of $15 \mathrm{~s}$ per step at $15 \mathrm{kV}, 15 \mathrm{nA}$, and $5-10 \mu \mathrm{m}$ beam diameter, resulting in a total counting time of 30 min per scan. ZnS (synthetic) and baryte (natural) standards were used to define the $S^{2-}$ and $\mathrm{S}^{6+} \mathrm{K} \alpha$ emission lines. The difference of both peaks was found to be in good agreement with literature data (Matthews et al. 1999; Höflich et al. 2004). Before each scan on an unknown sample, the $\mathrm{S}-\mathrm{K} \alpha$ peak position on the $\mathrm{ZnS}$ standard was checked to compensate any machine drift. It has to be pointed out that the build-in software for the spectrometer wavelength-scan procedure of the manufacturer of the microprobe was not precise enough to fulfill the requirements of an exact peak position determination, neither on a sample nor on the standard. Hence, a long time counting was applied also for the peak search on the standard. A Gaussian peak shape was applied for $\mathrm{S}^{2-}$ and $\mathrm{S}^{6+}$ lines to deconvolute both emission lines. Reference samples with known sulfur valence state: synthetic $\mathrm{ZnS}$ $\left(\mathrm{S}^{2-}\right)$, baryte $\left(\mathrm{S}^{6+}\right)$, natural meionite scapolite (mainly $\mathrm{S}^{6+}$ ) and natural glasses VG-2 $\left(\mathrm{S}^{2-}\right)$ and ALV981R23 $\left(\mathrm{S}^{2-}\right)$ (Jarosewich et al. 1980; Mosbah et al. 1991; Metrich and Clocchiatti 1996) were measured with the same procedure every day during the period of measurements. 
Since the "peak-integrated" mode needed at least 45 min for peak fit on the standard and analyzing the unknown sample, we needed to avoid affecting the sulfur in the sample, either driving it out or changing its valency state due to beam damage in the glass sample through a reduction reaction turning $\mathrm{S}^{6+}$ into $\mathrm{S}^{2-}$ (personal communication $\mathrm{S}$. Weinbruch, Darmstadt). Thus we decided to apply a more simple method to determine the sulfur content of both species:

First the exact spectral positions of the $\mathrm{K} \alpha$-lines for $\mathrm{S}^{2-}$ and $\mathrm{S}^{6+}$ on $\mathrm{ZnS}$ and baryte were determined. Then, the $\mathrm{S}-$ $\mathrm{K} \alpha$ signal was measured on both wavelength positions of the $S^{2-} \mathrm{K} \alpha$ - and $\mathrm{S}^{6+} \mathrm{K} \alpha$-emission lines during each quantitative analysis. Each raw signal was quantified separately, taking into account that both signals were overlapping.

This procedure followed the approach of Höflich et al. (2004) and provided reliable results if: (1) the peak shape of the $\mathrm{S}-\mathrm{K} \alpha$ emission lines can be described as Gaussian, (2) no peak-height to peak-area deviation occurred, (3) the peak shift was only a function of the valency state, and (4) no intermediate valency state between $\mathrm{S}^{2-}$ and $\mathrm{S}^{6+}$ occurred. For quantification scapolite and natural glasses VG2 and ALV981R23 were used as standards.

Both methods, "peak-area scan" and the "simple", peak counting method, have been applied to the same samples and gave a comparable result, which differ less than 10-15\% from each other. Thus, our "simple" approach led to a significantly shorter total counting time on both sulfur signals (240 s) but still maintained the analytical accuracy needed for this study.

Sulfide globules were found in most melt inclusions and did not disappear completely after heating. Metrich et al. (1999) showed that such globules persist even after 14$16 \mathrm{~h}$ of heating. However, the volume ratio of remaining sulfide globules versus glass inclusion was nearly constant (about 1/100) in most samples (Fig. 3b, d, e), irrespective of whether there were a single globule of large size (Fig. 3b, d, e) or several small globules (Fig. 3a, c, d).

Sulfide inclusions in the host olivine phenocrysts (Fig. 3f) were rare, only few were found in olivines from Gamchen lava (EVF, Table 3). With the latter exception, this may suggest that Kamchatka melts were not sulfursaturated before entrapment of the melt inclusions. The compositions of sulfide globules in the melt inclusions were also different from those in host olivine phenocrysts ( $\mathrm{Ta}$ ble 3), they were characterized by higher Fe, $\mathrm{Ni}$ and $\mathrm{Co}$ and lower $\mathrm{Cu}$ contents. Hence, the size of sulfide globules in melt inclusions and their distinct composition both indicated that they were daughter phases in the inclusions and not exsolved sulfide that formed before entrapment. Rather, they formed due to changes in $\mathrm{P}, \mathrm{FeO}, \mathrm{H}_{2} \mathrm{O}$ or $\mathrm{fO}_{2}$ after entrapment (e.g. Metrich et al. 1999; Danyushevsky et al. 2002).

The initial sulfur concentration could thus be calculated as $\mathrm{S}_{\text {initial }}=\mathrm{S}_{\text {melt }}+\mathrm{S}_{\text {sulfide }}$. Based on the relative abundances of sulfides, densities and $\mathrm{S}$ concentrations, we calculated that the additional contribution of sulfide sulfur to the melt to be about $600 \mathrm{ppm}$, which is comparable with previously published data (Metrich et al. 1999). The sulfur data presented in Table 2 and eTable 1 are recalculated values using a combination of glass analyses and backcalculation of sulfide globule contents. However, some inclusions had higher sulfide/melt inclusion volume ratios and resulting sulfur content should thus be considered as minimum values.

\section{Results}

Major, trace and volatile element compositions of the reheated melt inclusions and $\mathrm{Mg \#}[=100 \times \mathrm{Mg} /(\mathrm{Mg}+\mathrm{Fe})]$ of their host olivines are presented in Table 2 and eTable 1, 2. Fractional crystallization and degassing may have modified the initial signature of the mantle-derived primary magmas and thus could explain some variations in volatiles and incompatible elements in different samples.

As trace elements and volatiles are affected by differentiation and degassing, care must be taken when comparing data from samples with different degrees of differentiation as measured by Fo content of the host. Figure 4 a shows variations in potassium in melt inclusions for different host olivine composition.

The calculated differentiation paths with which to compare observed compositions are also shown. Most samples show some potassium enrichment due to fractional crystallization (decreasing Fo at increasing K). However, there is a clear enrichment independent of differentiation in potassium and phosphorus from EVF to CKD and SR, as observed also in the whole rock data.

Table 3 Composition of the sulfide globules in melt inclusions and olivine phenocrysts

\begin{tabular}{llllllllr}
\hline Description & $n^{\mathrm{a}}$ & $\mathrm{Si}$ & $\mathrm{Fe}$ & $\mathrm{Mn}$ & $\mathrm{Ni}$ & $\mathrm{Cu}$ & $\mathrm{Co}$ & $\mathrm{S}$ \\
\hline Sulfide globule in MI & 4 & $0.42^{\mathrm{b}}$ & 55.43 & 0.06 & 4.53 & 4.05 & 0.23 & 35.26 \\
Sulfide globule in olivine & 6 & 0.10 & 36.34 & 0.03 & 0.37 & 28.17 & 0.06 & 34.93 \\
\hline
\end{tabular}

\footnotetext{
${ }^{\text {a }}$ Number of analyses

b Recalculated to $100 \mathrm{wt} \%$
} 


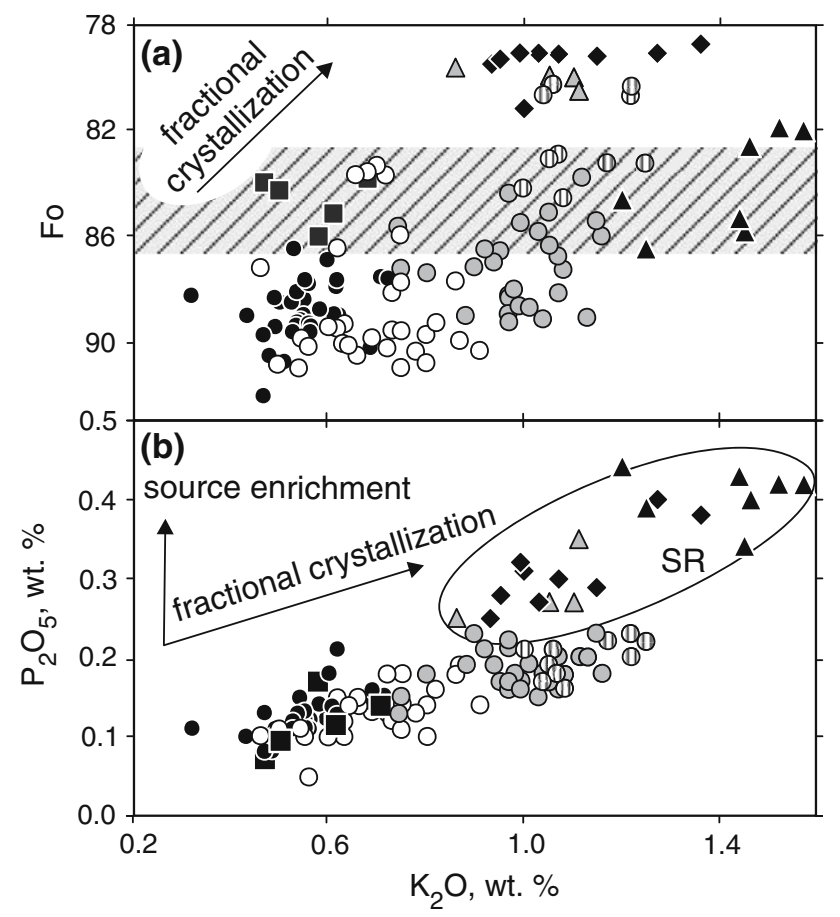

Fig. 4 Fo (a) and $\mathrm{P}_{2} \mathrm{O}_{5}$ (b) versus $\mathrm{K}_{2} \mathrm{O}$ diagrams show the major element composition of the reheated melt inclusions. Potassium and phosphorus increase in melts as Forsterite decreases due to fractional crystallization. The melt inclusions from olivines of the same Forsterite (shaded area) from the three different volcanic zones show potassium enrichment from the arc front to back arc (a). Independent enrichment in phosphorus demonstrates the enriched component in melts of the SR back arc (b). Symbols as in Fig. 2
Incompatible trace element ratios cannot change significantly with differentiation and must represent primary values. Therefore we use trace element ratios in our future discussions on melt composition evolution rather than absolute trace element abundances.

Across-arc volatile element variations

To minimize the possible effects of differentiation and degassing we present volatile contents normalized to an incompatible element (Fig. 5). We choose $\mathrm{Yb}$ for normalization because it is independent of variable mantle components (depleted MORB vs. OIB mantle).

Figure $5 \mathrm{a}, \mathrm{b}$ show that the highest $\mathrm{S} / \mathrm{Yb}$ ratios are observed in CKD melts while $\mathrm{Cl} / \mathrm{Yb}$ is similar for $\mathrm{EVF}$ and CKD. Both ratios gradually decrease from the volcanic front to the back arc. In contrast, the $\mathrm{F} / \mathrm{Yb}$ ratio increases and even the least enriched sample of the $S R$ has $F / Y b$ values are two to three times higher than least enriched samples from EVF and CKD (Fig. 5c). Due to this chlorine depletion and fluorine enrichment, the $\mathrm{F} / \mathrm{Cl}$ ratio progressively increases from the arc front to the back arc (Fig. 5d).

Trace element data

Trace elements patterns of melt inclusions mimic acrossarc geochemical variations, as previously documented for whole rock data (Churikova et al. 2001). All measured
Fig. 5 Correlations between $\mathrm{S} / \mathrm{Yb}(\mathbf{a}), \mathrm{Cl} / \mathrm{Yb}(\mathbf{b}), \mathrm{F} / \mathrm{Yb}$ (c) and $\mathrm{F} / \mathrm{Cl}$ ratio $(\mathbf{d})$ in reheated melt inclusions and slab depth. Symbols as in Fig. 2
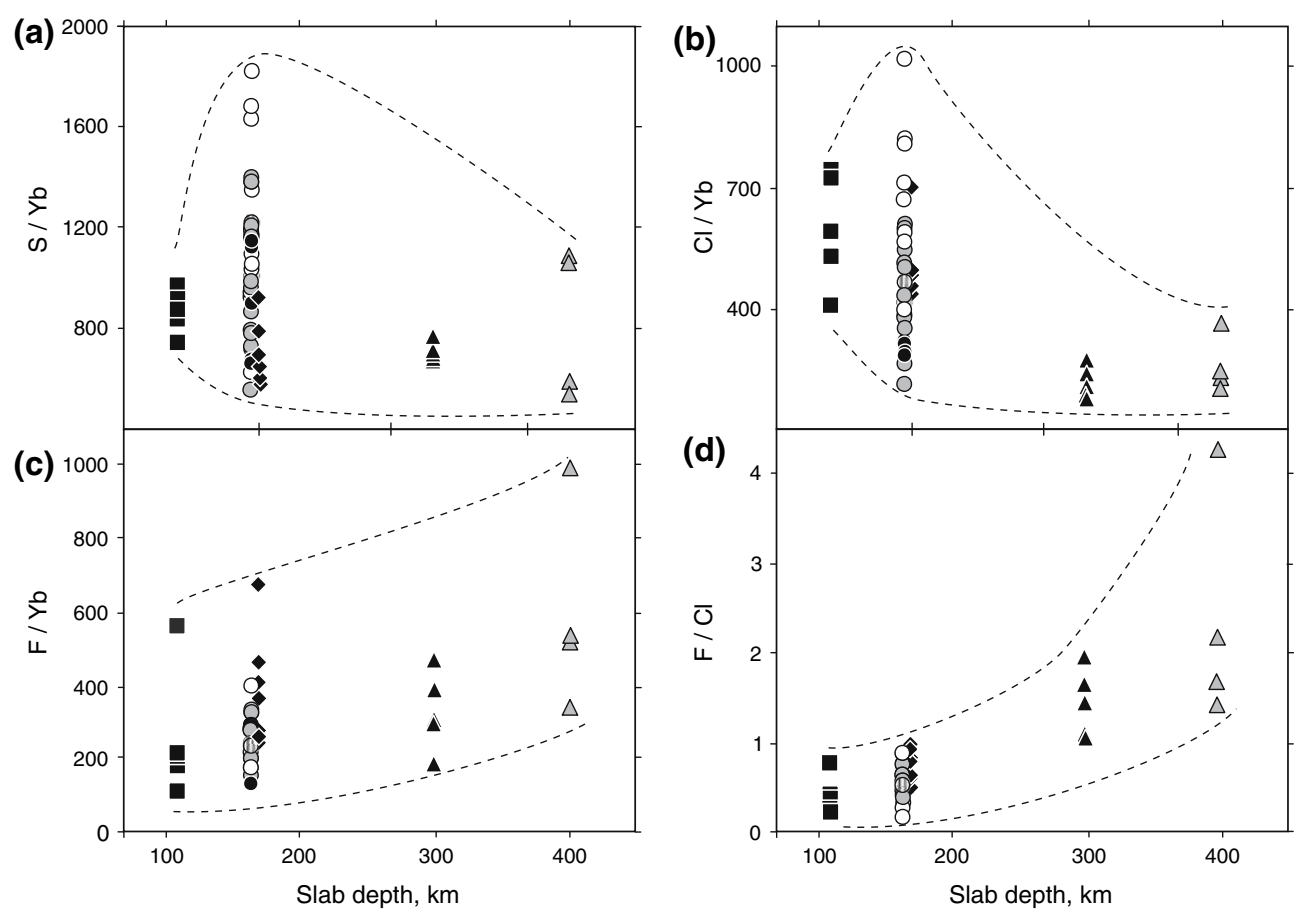
inclusions have typical arc-signatures with strong but variable LILE and LREE enrichment and low HFSE (Fig. 6; Table 2). LILE and HFSE concentrations increase from the arc front to the back arc. All melts are depleted in $\mathrm{Nb}$ relative to $\mathrm{Ba}$ or $\mathrm{La}$, but for SR this depletion is less pronounced than for CKD and EVF samples. HREE are much lower than in NMORB and change only slightly between the three groups (hence normalization of volatiles to $\mathrm{Yb}$, see below).

Compared to whole rock data, the concentrations of incompatible trace elements and their ratios in inclusions show a greater range (especially for CKD samples). A
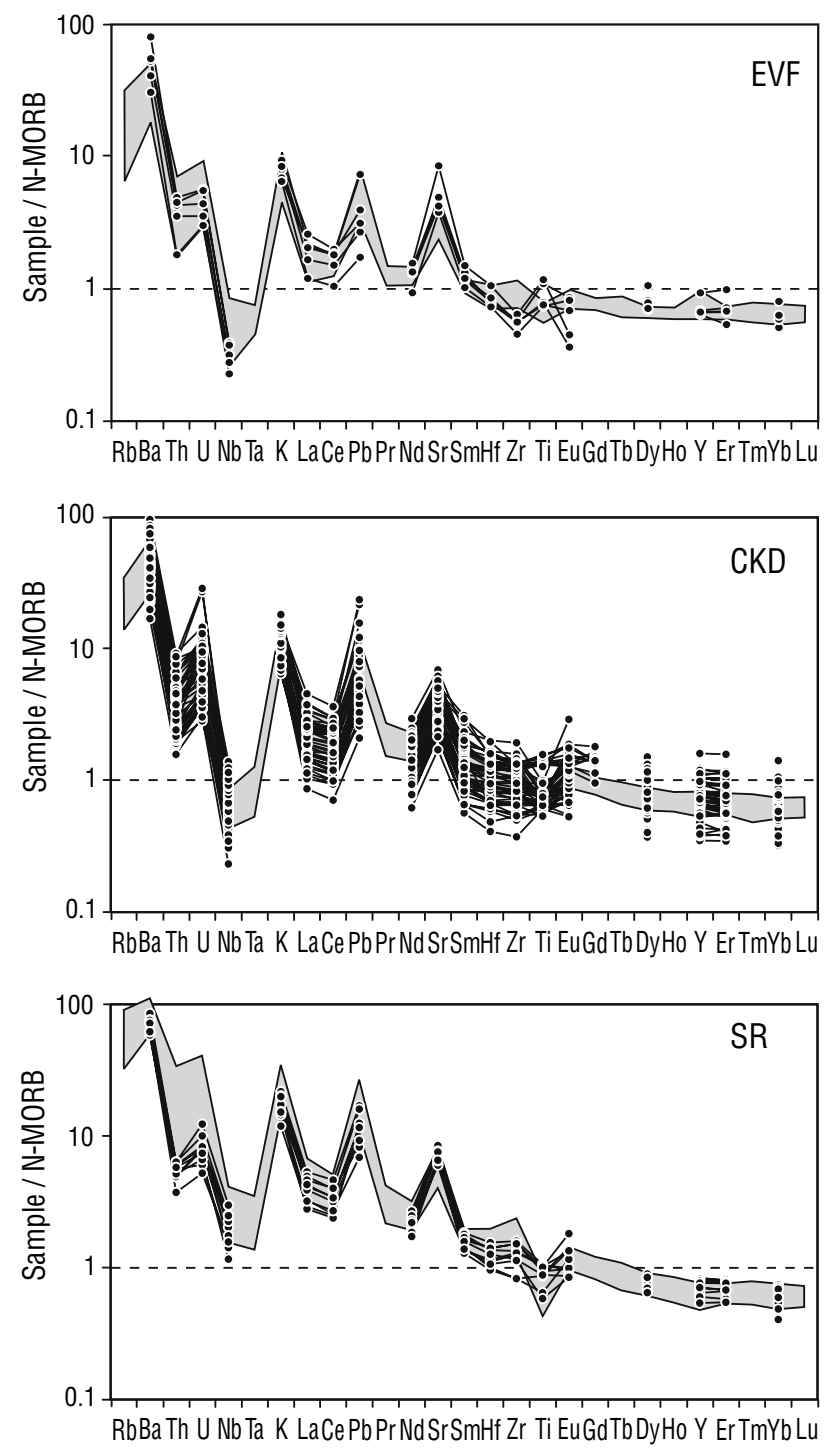

Fig. 6 Primitive mantle-normalized trace element patterns (black lines) for reheated melt inclusions in olivines of the different regions of the North Kamchatka transect. N-MORB and Primitive mantle values are from Sun and McDonough (1989). The shaded fields show the range of whole rock data for comparison similar effect has been previously described by Sobolev et al. (2000) who suggested that melt inclusion data better record heterogeneities in melt compositions at depth. By contrast, lavas are more strongly affected by mixing resulting in more homogenous compositions.

All incompatible elements are generally correlated (Fig. 7a, b). In detail, however, incompatible trace element ratios are variable, suggesting different sources for EVF, CKD and SR lavas (Fig. 7c, d). CKD melt inclusions are enriched in all incompatible elements compared to EVF inclusions. However, the EVF and CKD melts form a common field close NMORB. Melt inclusions from Sredinny Ridge lavas show variable enrichment in trace elements. This enrichment is attributed to the mixing of NMORB and OIB magma sources in the mantle wedge.

\section{Discussion}

Before we discuss the observed changes in volatiles across the arc and their potential connection with different fluid sources, we need to look in more detail into volatile behavior during magma evolution.

Variations in volatiles during melt evolution

Volatile elements are potentially affected by (1) depletion due to crystallization of volatile-bearing phases, (2) accumulation during fractional crystallization, (3) degassing, (4) mixing of different melts, and (5) melts derived from different mantle sources. In order to assess possible variation in fluid chemistry of the magma sources along the descending slab (5), we first discuss these other processes during magma ascent (1), (2) and close to the surface (3). Because no halogen-bearing minerals such as amphibole, apatite or phlogopite have been observed, the behavior of halogens is not influenced by (1). Sulfur concentration is corrected for sulfide fractionation inside melt inclusions and the majority of lavas are sulfide under-saturated (see above). Thus, fractionation of volatile-bearing phases (1) is essentially ruled out.

$\mathrm{S}, \mathrm{Cl}$, and $\mathrm{F}$ behave as incompatible elements and accumulate in silicate melts during fractional crystallization and may reach saturation, which results in degassing (Carrol and Webster 1994). S solubility decreases at lower $\mathrm{FeO}$ and increases with $\mathrm{fO}_{2}$ up to the NNO buffer (Carrol and Webster 1994). Due to $\mathrm{FeO}$ decrease caused by crystallization of olivine, pyroxene and magnetite and increasing $f \mathrm{O}_{2}$ during melt evolution, the sulfur solubility should decrease in basaltic melt and sulfur degassing becomes likely even before entrapment of melt inclusion.

Aqueous fluid-melt partition coefficients for $\mathrm{Cl}$ vary over several orders of magnitude (e.g., Bureau et al. 2000; 
Fig. 7 Trace elements (a, b) and trace element ratios $(\mathbf{c}, \mathbf{d})$ in reheated melt inclusions are well correlated within individual samples. Melts of the SR back arc are enriched in all incompatible elements and trace element ratios due to OIB addition in the source. EVF melts have the lower trace element ratios compared to CKD due to a larger degree of melting. Symbols as in Fig 2
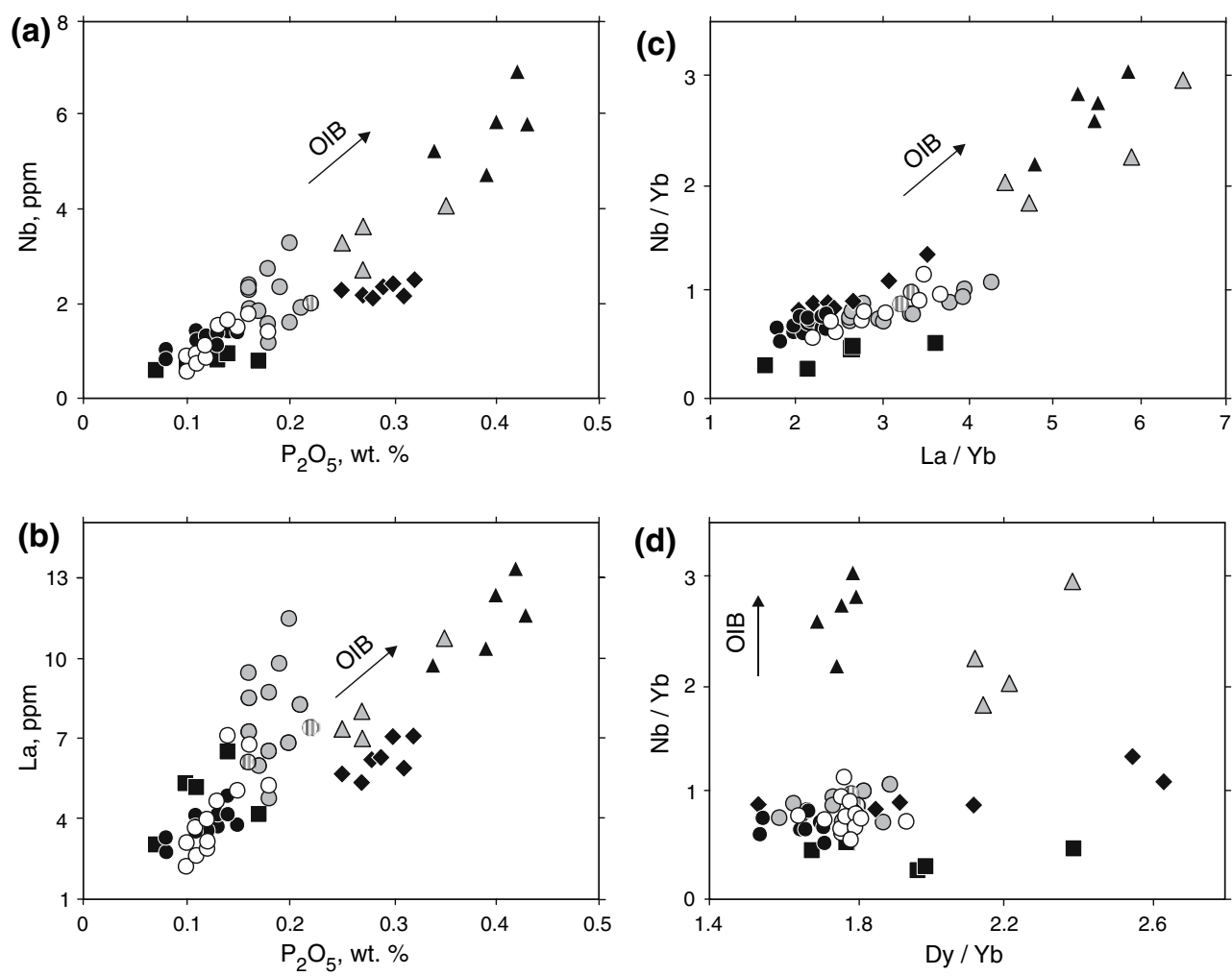

Edmonds et al. 2001) and depend strongly on melt and fluid compositions (mainly $\mathrm{H}_{2} \mathrm{O}$ ) as well as $P-T$ conditions (Carrol and Webster 1994). Despite high chlorine solubility in mafic melts (e.g., Lassiter et al. 2002), $\mathrm{Cl}$ degassing is recorded in numerous examples (e.g., Hansteen and Gurenko 1998).

Fluorine is more soluble in the silicate melt (Rowe and Schilling 1979), but comparison of fluorine contents in matrix glasses and melt inclusions show (Carrol and Webster 1994) that this element can also be affected by degassing.

$\mathrm{K}(\mathrm{Ce}, \mathrm{P})$ behaves as strongly incompatible element similar to volatiles (Figs. 4b, 7a, b) but is not affected by degassing. On the diagrams volatile $/ \mathrm{K}_{2} \mathrm{O}$ versus $\mathrm{Fo}$ both fractional crystallization and degassing are recognized (Fig. 8). $\quad \mathrm{S} / \mathrm{K}_{2} \mathrm{O}$ decreases with differentiation (e.g., decreasing Fo) in all samples but does not change in SR melts (Fig. 8a). Cl/ $\mathrm{K}_{2} \mathrm{O}$ decreases in melts from EVF and Kluchevskoy but not for SR and Kamen samples (Fig. 8b). $\mathrm{F} / \mathrm{K}_{2} \mathrm{O}$ does not change with Fo in EVF and Kluchevskoy melts but shows strong enrichment within the SR and Kamen samples (Fig. 8c). Figure 8d shows that sulfur has degassed to a large extend in many samples as opposed to chlorine.

Several conclusions can be drawn from these observations:

1. Sulfur and chlorine are affected by degassing to different extends in most melts from EVF and CKD, but not in the SR samples.
2. Chlorine is less degassed compared to sulfur and may not degas at all and accumulate in the melt during fractionation (e.g. Kamen and SR).

3. Fluorine is not affected by degassing in studied melt inclusions and shows some minor enrichment for SR and Kamen samples.

4. Taking the volatile/ $\mathrm{K}_{2} \mathrm{O}$ ratio from the least differentiated melt in the most magnesian Fo allows us to identify the undegassed endmembers of these degassing trends.

Sulfur, chlorine and fluid-mobile elements

$\mathrm{Cl} / \mathrm{Nb}$ ratios are on average higher in EVF compared to $\mathrm{CKD}$ while $\mathrm{S} / \mathrm{Nb}$ ratios are the same in both and higher than in samples from SR (Fig. 9). In comparison with SR melts, melt inclusions from EVF and CKD are enriched in both ratios but almost do not overlap. This enrichment is correlated with B/Nb (Fig. 9a, b), suggesting that a B-rich fluid controls $\mathrm{S}$ and $\mathrm{Cl}$ in Kamchatka lavas. EVF and CKD melts have also higher $\mathrm{U} / \mathrm{Nb}, \mathrm{Th} / \mathrm{Nb}, \mathrm{Ba} / \mathrm{Nb}, \mathrm{K} / \mathrm{Nb}$ and $\mathrm{Pb} /$ $\mathrm{Nb}$ ratios (Fig. 9, two last not shown).

The enrichment of EVF and CKD melt inclusions in U, $\mathrm{Th}, \mathrm{K}, \mathrm{Ba}, \mathrm{La}, \mathrm{Pb}$ and the positive correlation of these elements with B suggests that the B-rich fluid also carries these elements. Our melt inclusion data are in agreement with previously published results (Ryan et al. 1995; Ishikawa and Tera 1997; Ishikawa et al. 2001; Wörner et al. 
Fig. 8 Variation in $\mathrm{V} / \mathrm{K}_{2} \mathrm{O}$ ( $\mathrm{V}=$ volatile element $)$ with $\mathrm{Mg} \#$ of host olivines. The $\mathrm{S}$ versus $\mathrm{Cl}$ diagram $(\mathbf{d})$ shows that sulfur is more strongly degassed than chlorine. f.c. fractional crystallization. Symbols as in Fig. 2
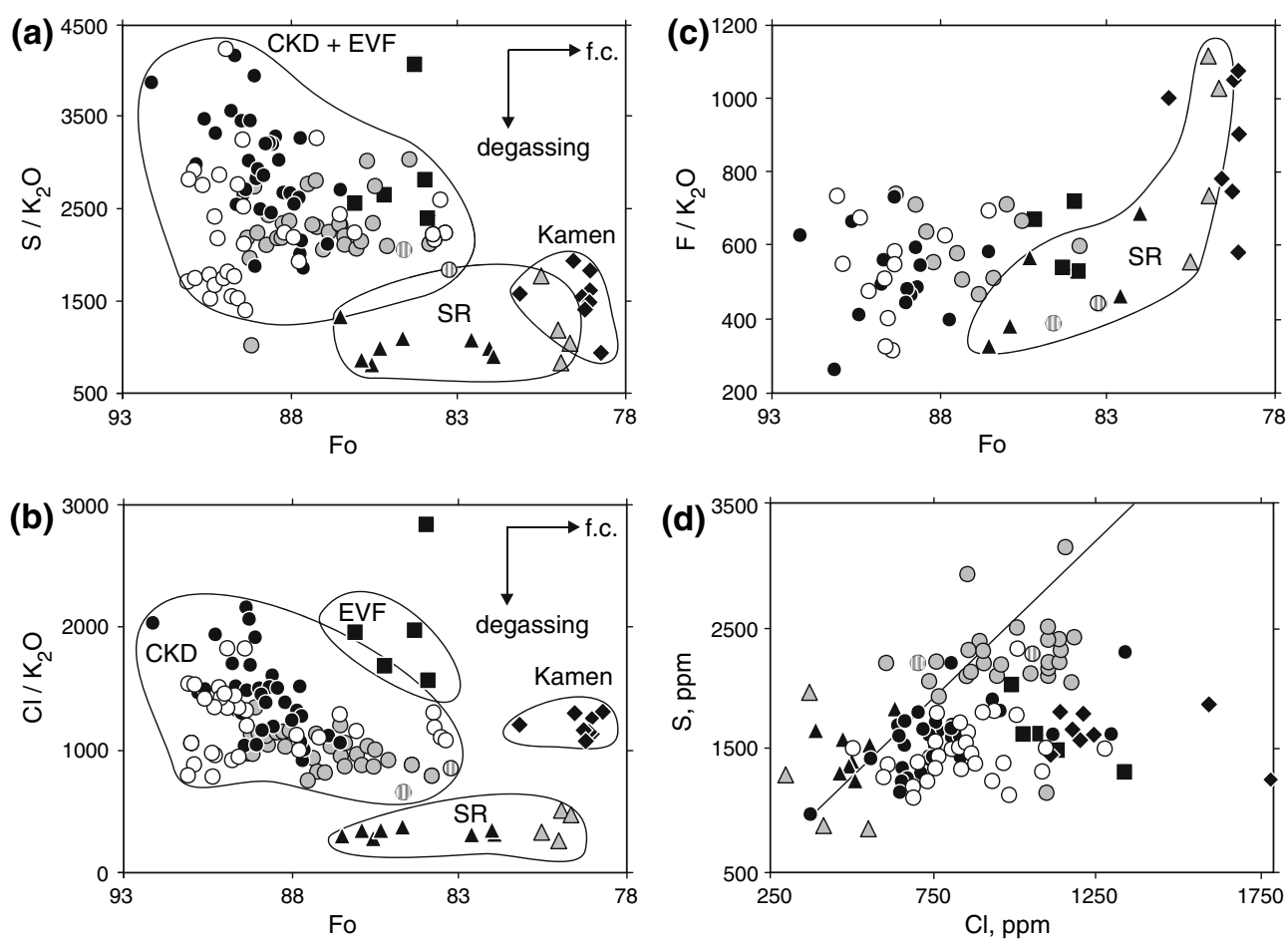

2001), suggesting that B-rich fluids are contributed in EVF and CKD regions.

In detail, however, a significant difference in fluid compositions is observed between EVF- and CKD-fluids. EVF melts show higher enrichment in $\mathrm{Ba} / \mathrm{Nb}, \mathrm{Ce} / \mathrm{Nb}$ and $\mathrm{La} / \mathrm{Nb}$ and less so for $\mathrm{B} / \mathrm{Nb}$ and $\mathrm{Th} / \mathrm{Nb}$ (Fig. 9) compared to CKD melt inclusions. This enrichment is coupled with high chalcophile element contents (Wörner et al 2001). U/Th ratios in CKD melts are up to two to three times higher than in the EVF (Fig. 10). This enrichment is entirely consistent with whole rock analyses and argues for a U-rich CKD fluid, which is distinct from the fluids at the arc front (EVF).

On the other hand, the CKD melts show the highest $\mathrm{S}$ and $\mathrm{S} / \mathrm{Nb}$ values. This enrichment is coupled with high ${ }^{87} \mathrm{~S} /{ }^{88} \mathrm{Sr}$ in whole rocks. In Kamchatka, where sediments play a minor role, the fluids driving arc magmatism are derived dominantly from the altered subducted oceanic crust with high ${ }^{18} \mathrm{O}$ (Dorendorf et al. 2000a). Recently Ishikawa et al. (2001) and Wörner et al. (2001) found that $\mathrm{CKD}$ rocks are also enriched in ${ }^{11} \mathrm{~B}$ isotopes (three to ten times) compared to the neighboring EVF region of our transect.

\section{Subducted Hawaiian Seamount chain as fluid source} in the arc front

Because the mantle is relatively depleted in chlorine, the main source of this element in subduction setting is sub- ducted oceanic crust. The Hawaiian Seamount chain, which is being subducted below Kamchatka, however, could release particularly large amounts of chlorine. This is confirmed by the high magma production rate in the region and particular by the existence of the Kluchevskaya Group of volcanoes, which is situated just inboard of the subducted seamounts. If the Hawaiian Seamount chain plays an important role in transferring volatiles to the mantle wedge, then a significant difference in the fluid component contribution should be observed between our Kamchatka transect in the $\mathrm{N}$ and volcanoes to the south, away from the seamounts. Published data show that lavas of the volcanoes to the south have higher ${ }^{206} \mathrm{~Pb} /{ }^{204} \mathrm{~Pb}$ (Castellana 1998; Turner et al. 1998; Dorendorf et al. 2000b), ${ }^{11} \mathrm{~B}$ isotopes and $\mathrm{B} / \mathrm{Nb}$ ratios (Ishikawa et al. 2001). These observations underline the distinct character of our transect rocks and emphasize the important role of the subduction of the seamount chain there.

However, no data exist on volatile elements $(\mathrm{S}, \mathrm{Cl}$ and F) in sources for the southern Kamchatka volcanoes and more research on volatiles must be done on other Kamchatka volcanoes away from the subducted seamounts to support our case.

Fluorine and source enrichment in back arc lavas

$\mathrm{F} / \mathrm{Yb}$ ratios are plotted versus trace element ratios in Fig. 11. Due to similar crystal-melt partitioning, incompatible elements ratios such as $\mathrm{Li} / \mathrm{Yb}, \mathrm{Li} / \mathrm{Dy}, \mathrm{B} / \mathrm{Yb}, \mathrm{B} / \mathrm{La}$, 


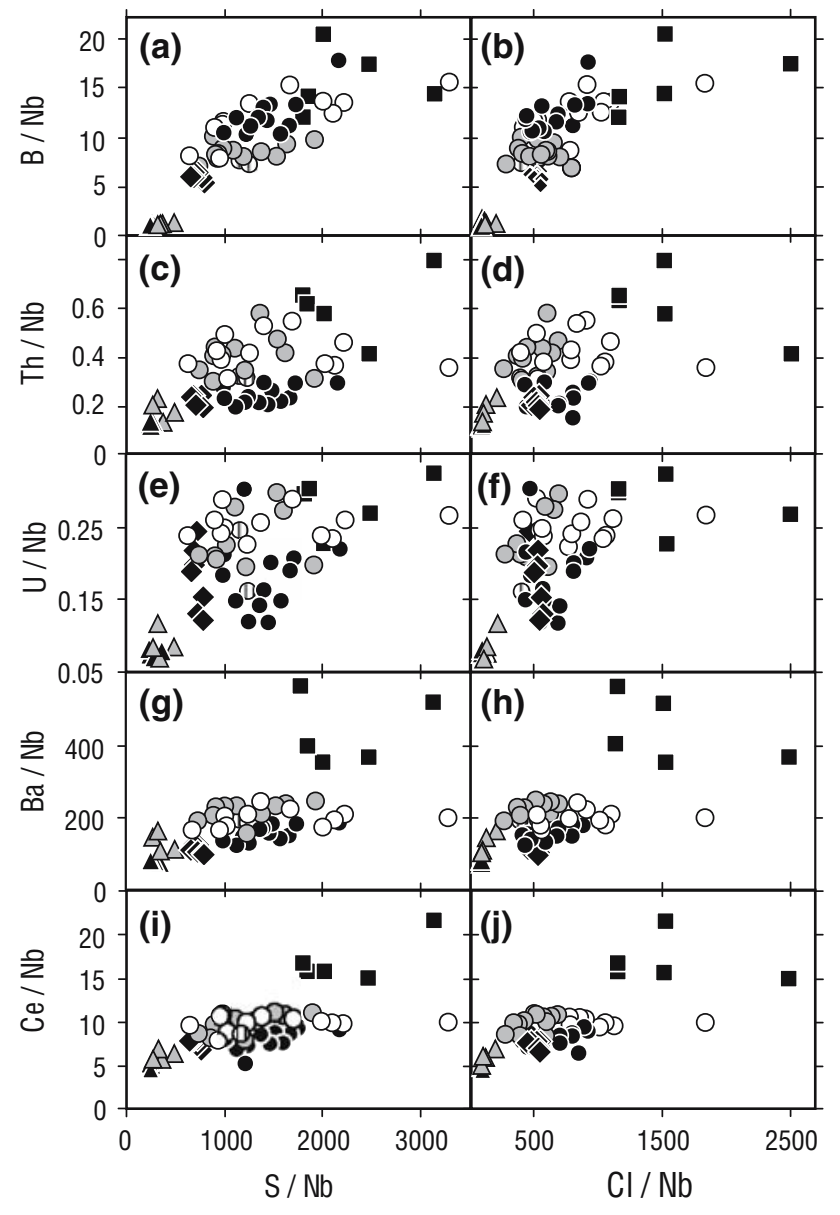

Fig. $9 \mathrm{~S} / \mathrm{Nb}$ and $\mathrm{Cl} / \mathrm{Nb}$ versus trace element ratios. High concentrations of $\mathrm{S}$ and $\mathrm{Cl}$ in melts from EVF and CKD are coupled with enrichment in B (a, b), LILE (c-h) and LREE (i-j) in frontal part of the Kamchatka arc. Symbols as in Fig. 2

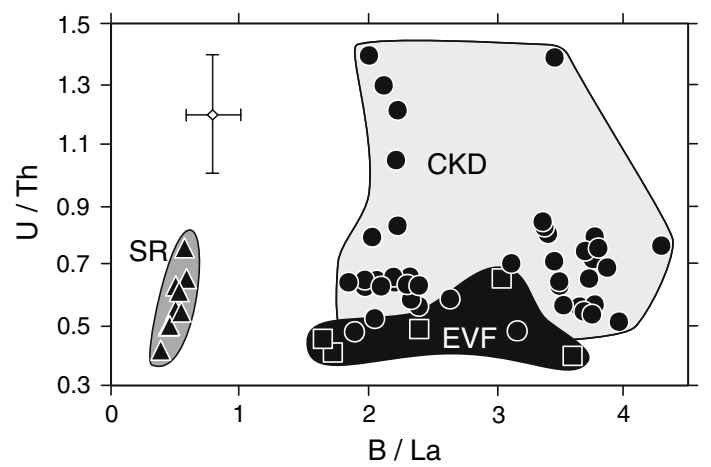

Fig. $10 \mathrm{~B} / \mathrm{La}$ versus U/Th in melt inclusions. Gray fields show the three volcanic zones along the Northern Kamchatka transect. Samples from Kluchevskoy volcano are enriched in U/Th compared to EVF melts, suggesting a distinct fluid composition in this region

$\mathrm{Ba} / \mathrm{La}, \mathrm{Sr} / \mathrm{Y}, \mathrm{Nb} / \mathrm{Yb}$ and $\mathrm{F} / \mathrm{Yb}$ are considered to remain unfractionated during $>5 \%$ mantle melting and crystallization processes and thus represent source values (Ryan and Langmuir 1987; McDonough and Sun 1995).
Samples from EVF and Kluchevskoy volcano (CKD) show good correlations of $\mathrm{F} / \mathrm{Yb}$ with $\mathrm{B} / \mathrm{Yb}$, but not with $\mathrm{Li} /$ $\mathrm{Yb}$, suggesting that mainly a boron rich fluid is responsible for the fluorine in their source. In contrast, $\mathrm{F} / \mathrm{Yb}$ in $\mathrm{SR}$ samples correlates with $\mathrm{Li} / \mathrm{Yb}$ but not with $\mathrm{B} / \mathrm{Yb}$ (Fig. 11a, b). In this case, the Li-rich source also contributes fluorine in the back arc. Samples from Kamen volcano (CKD) are enriched in all three ratios resulting in positive trends on both diagrams, which suggest the influence of both, B- and Li-rich components.

On the $\mathrm{F} / \mathrm{Yb}(\mathrm{Y})$ and $\mathrm{Nb} / \mathrm{Yb}(\mathrm{Y})$ diagram the relative enrichment of the melts from the three zones is demonstrated (Fig. 11c). CKD melts are enriched in $\mathrm{Nb} / \mathrm{Yb}$ compared to EVF due to smaller melting degree, but depleted compared to SR melt inclusions. Strong $\mathrm{Nb}$ enrichment in SR has been attributed to the involvement of an OIB component in the melting region (Churikova et al. 2001; Münker et al. 2004). Nb is known as a conservative element with respect to fluids.

However, a positive correlation is found in back arc rocks between $\mathrm{F} / \mathrm{Yb}$ and $\mathrm{Nb} / \mathrm{Yb}$ (Fig. 11c), suggesting that at least some $\mathrm{F}$ is derived from the (Nb-) enriched OIB component in their source. For CKD and EVF, this correlation is weak or absent. By contrast, EVF and CKD melts show good correlations for $\mathrm{F} / \mathrm{Yb}$ with fluid-mobile elements $(\mathrm{B} / \mathrm{Yb}, \mathrm{Ba} / \mathrm{Yb}$, and $\mathrm{Sr} / \mathrm{Yb}$, Figs. 11a, 12a-c). The B-rich arc-front fluid therefore must have carried some fluorine along with these elements. The fluids are also different with respect to $\mathrm{Li}$. $\mathrm{Li} / \mathrm{Yb}$ is correlated with fluorine only in the SR back arc and for melts from Kamen (Fig. 12d). There is no correlation between $\mathrm{Li}$ and $\mathrm{F}$ for the arc front melts.

Thus, the arc-front and CKD fluids carry a significant amount of fluorine correlated with fluid-mobile elements, including $\mathrm{B}$ but not Li. Back arc fluorine is partly contributed by a deep fluid that carries some fluid-mobile elements including Li but no B. The second source for fluorine is the enriched OIB component.

The enrichment in trace elements in the back arc samples (elevated $\mathrm{Sr} / \mathrm{Y}, \mathrm{Ba} / \mathrm{Y}, \mathrm{Nb} / \mathrm{Yb}, \mathrm{Li} / \mathrm{Yb}$ and $\mathrm{F} / \mathrm{Y}$ ) is correlated with decreasing Mg\# of the host olivines (Fig. 8c). This implies that magmas from different sources may have mixed. These magmas would then have to have different amounts of the OIB component.

\section{OIB enrichment versus back arc fluid}

Churikova et al. (2001) suggested a contribution of 5\% of an OIB component in the mantle sources for back arc SR samples studied here. Li concentrations in oceanic basalts (4.3 ppm in MORB and $5.6 \mathrm{ppm}$ in OIB, after Sun and McDonough 1989) and $\mathrm{Li} / \mathrm{Yb}$ ratios in both sources (1.41 and 2.59, respectively) are rather close (see Figs. 11b, 


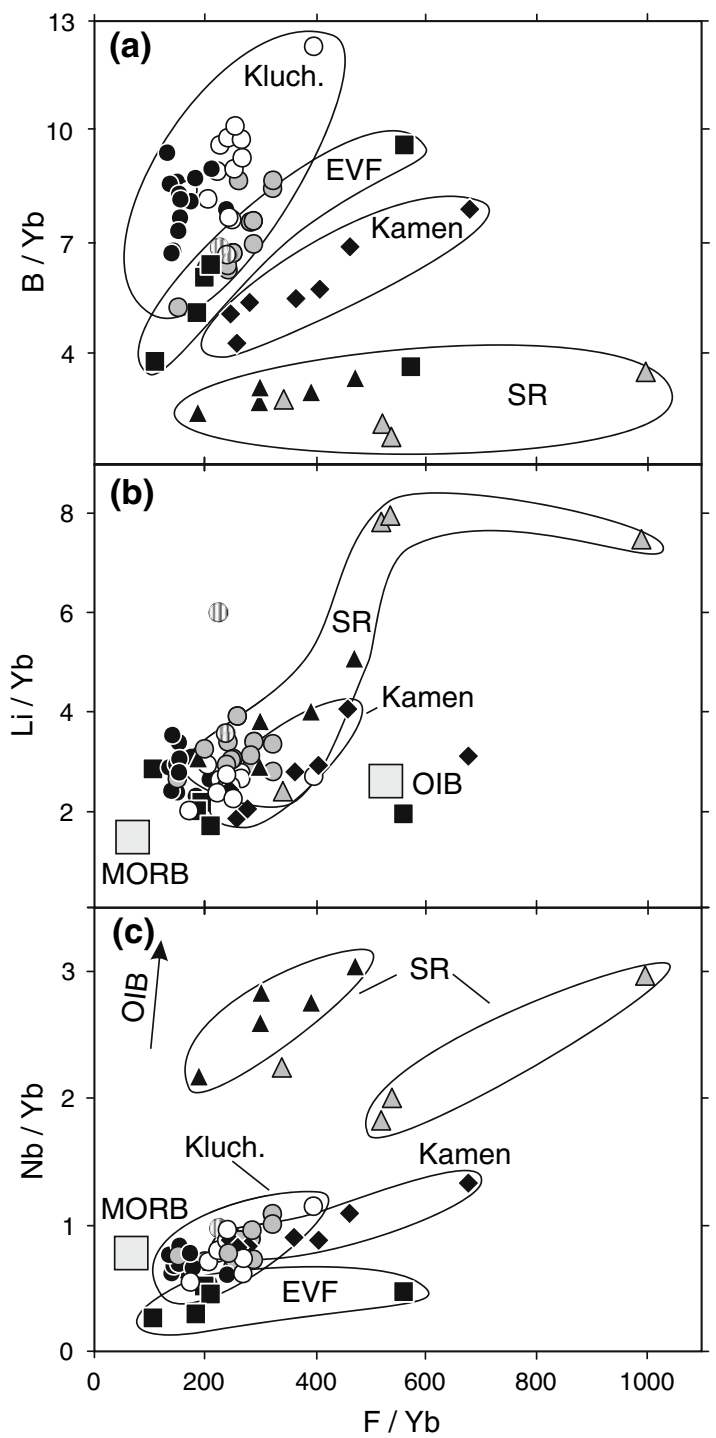

Fig. $11 \mathrm{~B} / \mathrm{Yb}(\mathbf{a}), \mathrm{Li} / \mathrm{Yb}(\mathbf{b})$ and $\mathrm{Nb} / \mathrm{Yb}(\mathbf{c})$ versus $\mathrm{F} / \mathrm{Yb}$ in reheated melt inclusions. F/Yb in EVF and CKD is positively correlated with $\mathrm{B} / \mathrm{Yb}$, but do not show any correlations with $\mathrm{Li} / \mathrm{Yb}$. In contrast, the SR back arc glasses show good correlation between $\mathrm{F} / \mathrm{Yb}$ and $\mathrm{Li} / \mathrm{Yb}$, but not between $\mathrm{F} / \mathrm{Yb}$ and $\mathrm{B} / \mathrm{Yb}$. $\mathrm{F} / \mathrm{Yb}$ positively correlates with all these ratios in Kamen melts. The positive correlation $\mathrm{F} / \mathrm{Yb}$ with $\mathrm{Nb} /$ $\mathrm{Yb}$ suggests that the mantle component is the additional source for fluorine in all volcanic zones. The fields indicate the positive correlations between $\mathrm{F} / \mathrm{Yb}$ and trace element ratios. MORB and $O I B$ components (after Sun and McDonough 1989) are shown for comparison. Symbols as in Fig 2

12d). The addition of 5\% OIB component would not significantly affect the $\mathrm{Li} / \mathrm{Yb}$ ratio in these melts. However, the $\mathrm{Li} / \mathrm{Yb}$ ratio varies in SR melt inclusions by a factor of 3 and exceeds that in melts from EVF and CKD by a factor of 5 (Fig. 11b).

At garnet stability field conditions for the OIB-component in the back arc, $\mathrm{Yb}$ is more compatible than $\mathrm{Li}$ and the melting behavior of Li must be rather similar to Dy (Ryan and Langmuir 1987). The Li/Dy ratio is even less variable in MORB and OIB (0.95 and 1), but again, Li/Dy changes from $0.8-1.2$ (EVF) to 1.1-2.2 (CKD) and increases up to $1.7-3.7$ in SR inclusions.

Moreover, despite that $\mathrm{Ba} / \mathrm{Yb}$ and $\mathrm{Sr} / \mathrm{Yb}$ are higher in OIB sources compared to MORB (12.07 and 0.23, 22.76 and 3.21, respectively) these ratios in SR melts are all higher still than in OIB (Fig. 12). Thus, it is impossible to explain the enrichment of SR melts in $\mathrm{Li} / \mathrm{Yb}$ and $\mathrm{Li} / \mathrm{Dy}$ only by mixing of MORB and OIB mantle sources and an additional source contribution from a slab fluid for these elements is required. Good correlations between these ratios and $\mathrm{Li} / \mathrm{Yb}(\mathrm{Y})$ and $\mathrm{F} / \mathrm{Yb}(\mathrm{Y})$ ratios (Fig. 12a, b) suggest that the fluid below SR is also enriched in $\mathrm{Ba}, \mathrm{Sr}$ and $\mathrm{Be}$ (not shown). Moreover, to reach the lowest $\mathrm{F} / \mathrm{Yb}$ ratio from the studied SR melts (189 in Achtang) required 35\% of OIB addition in the source, which is not consistent with our previous results.

\section{Li-rich fluids in Kamchatka back arc}

While mineral-fluid partition coefficients for $\mathrm{Li}$ are similar to mineral-melt values (Brenan et al. 1998a), the mineralfluid partition coefficient for $\mathrm{Yb}$ (and for Dy) is 1,000 times larger than those for mineral-melt pairs (Ryan and Langmuir 1987; Brenan et al. 1998a, b). Thus, the only process that could fractionate $\mathrm{Li}$ from $\mathrm{Yb}$ in subduction settings is fluid release (Brenan et al. 1998b) and interaction of the fluid phase with the mantle. Therefore back arc Li enrichment is probably also contributed from the fluid phase.

Ryan et al. (1995) suggested for the Kuril-Kamchatka arc that semi-mobile elements like Be and LREE may move from the subducted slab with fluids liberated at depth $>200 \mathrm{~km}$. Churikova et al. (2001) showed that about $50 \%$ of the Ce must be contributed by fluids in the deep SR source.

Recently, Stalder and Ulmer (2001), using high-pressure experiments (up to $14 \mathrm{GPa}$ ) showed that dense hydrous magnesian silicates (DHMS) such as clinohumite $\left(\mathrm{H}_{2} \mathrm{O}=2-3 \%\right)$ and "phase $\mathrm{A}$ " $\left(\mathrm{H}_{2} \mathrm{O}=13 \%\right)$ can carry about $10 \%$ of the initially subducted water to a depth of up to $400 \mathrm{~km}$. At such depth both phases become unstable and release a relatively small amount of water to the mantle wedge below the back arc. Additionally, at a depth below $10 \mathrm{Gpa}(300 \mathrm{~km})$, clinohumite becomes the stable Fbearing mineral: fluorine (up to $1 \%$ ) increases the thermal stability of the clinohumite (Stalder and Ulmer 2001) and may transport this volatile to the deep mantle wedge.

Deep fluids are more viscous and less mobile (Keppler 1996), but still could metasomatize the upper mantle (Stalder et al. 2001) below the back arc (SR) and produce melts relatively enriched in Li, F, LILE, and LREE, but also carry large amounts of nominally more immobile elements (e.g., HFSE). The subduction trace element patters, however, are still maintained. This is in fact observed 
Fig. $12 \mathrm{Sr} / \mathrm{Yb}($ a) and $\mathrm{Ba} / \mathrm{Yb}$ (b) versus $\mathrm{F} / \mathrm{Yb}$ and $\mathrm{Sr} / \mathrm{Yb}(\mathbf{c})$ and $\mathrm{Li} / \mathrm{Yb}(\mathbf{d})$ versus $\mathrm{Ba} / \mathrm{Yb}$ in reheated melt inclusions. The fields indicate the positive correlations between trace element ratios. $M O R B$ and $O I B$ components (after Sun and McDonough 1989) are shown for comparison. Discussion see in text. Symbols as in Fig 2

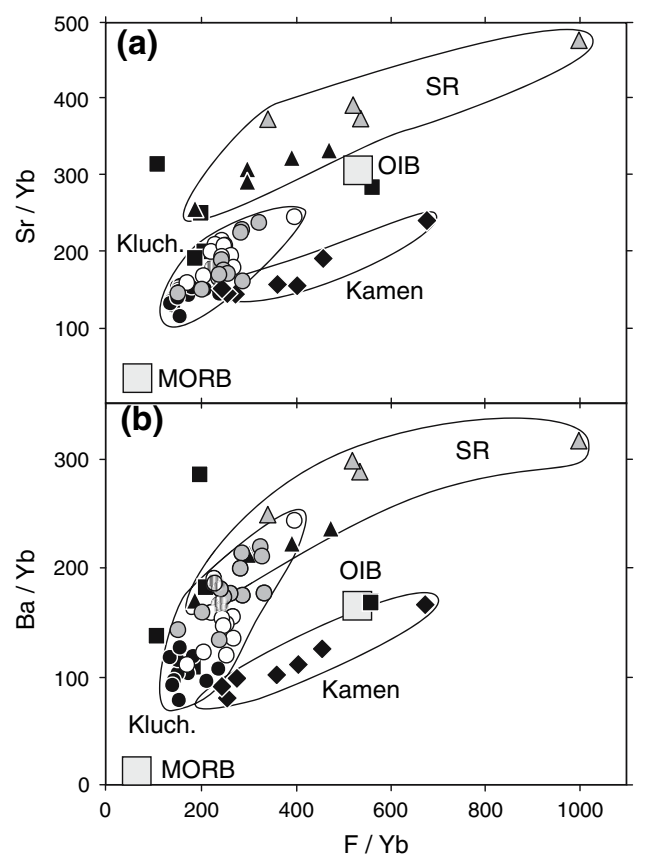

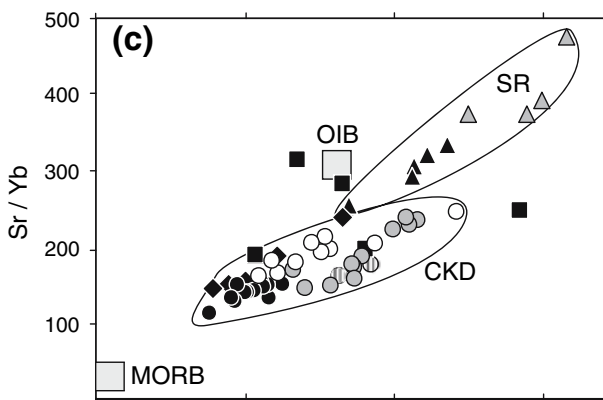

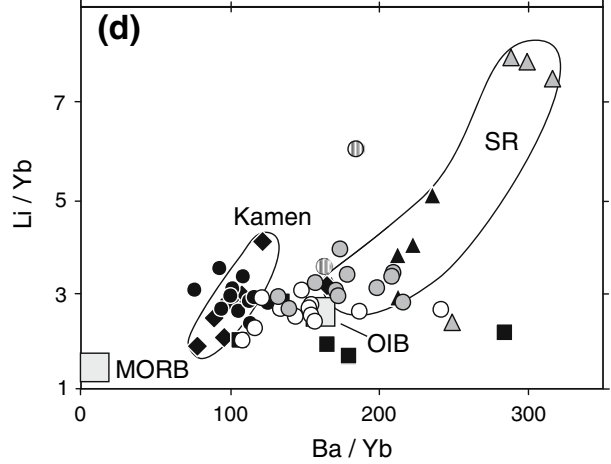

in SR back arc lavas and melt inclusions. We address this additional fluid enrichment in the modeling section (see below).

We do not imply, however, that the potential of fluid release down to $400 \mathrm{~km}$ implies melting at such depth below the Kamchatka back arc. Brenan et al. (1998a) provided geochemical and Gerya and Yuen (2003) presented modeling evidence that fluids released from the slab can cause melting within the mantle wedge at a location quite removed from the origin of the fluids. Thus, while magmatism occurs where the slab is at 300-400 km depth, the source and origin of the fluids and the melting process could actually be much shallower as indicated by the potentially highly complicated pattern of mantle wedge convection (Gerya and Yuen 2003).

Thus, our melt inclusion data provide clear evidence for existence of at least three chemically distinct fluids below the Kamchatka arc:

The first "EVF-fluid" is released in the frontal part of the arc and is highly enriched in $\mathrm{B}, \mathrm{Cl}$ and chalcophile elements. This fluid also carries LILE (Ba, Pb), U, Th, F, S, and LREE (La, Ce), but has relatively low U/Th. This fluid dominates EVF sources and is gradually depleted during slab dehydration. However, a significant contribution from this fluid is still observed in CKD volcanoes.

The second "CKD-fluid" affects the Kluchevskaya Group of volcanoes and is enriched in $\mathrm{S}, \mathrm{Cl}$ and $\mathrm{U}$, which results in the high $\mathrm{S} / \mathrm{P}_{2} \mathrm{O}_{5}, \mathrm{Cl} / \mathrm{P}_{2} \mathrm{O}_{5}$ and $\mathrm{U} / \mathrm{Th}$ ratios, but relatively lower $\mathrm{Cl} / \mathrm{S}$ compared to the $\mathrm{EVF}$-fluid.

The third "SR-fluid"' is enriched in F, Li and Be and still carries relatively large amounts of LILE and LREE.
This fluid starts to be released below CKD and becomes dominant in the back arc region.

\section{Li-B decoupling across the Kamchatka arc}

Boron is known as a highly fluid-mobile element in subduction fluids and strong B-enrichment has been repeatedly documented in the frontal zones of the volcanic arcs (Brenan et al. 1998b; Ishikawa and Tera 1997: Ishikawa et al. 2001). Our melt inclusion data and whole rock data for our transect (Wörner et al. 2001) clearly argue for a strong B enrichment in EVF and CKD magma sources by slab-derived fluids.

$\mathrm{Li}$ is enriched in marine sediments and weathered oceanic crust (Ryan and Langmuir 1987), which are the main Li reservoirs in subduction settings (Chan et al. 1999). Using $\mathrm{Pb}$ and $\mathrm{Be}$ isotope data, Kersting and Arculus (1995) and Tsvetkov et al. (1989) argued that subducted sediments play a minor role in magma generation below Kamchatka. $\mathrm{Pb}$ isotope data in our transect show slight enrichment (and probably only a very minor sediment component) in a few EVF lavas, but not in $\mathrm{CDK}$ and SR regions (Churikova et al. 2001). The variations in $\mathrm{Sr}$ and $\mathrm{O}$ isotope data show that the fluid is largely derived from the altered oceanic crust (Dorendorf et al. 2000a) rather than terrigenous and pelagic sediments. Hence, such subducted sediments are ruled out as significant Li reservoir in the back arc source.

Melt inclusions from Kamchatka show clear decoupling of B- and Li-rich fluids: while the melts from EVF and $\mathrm{CKD}$ are enriched in $\mathrm{B} / \mathrm{La}$, SR melt inclusions show enrichment in $\mathrm{Li} / \mathrm{Yb}$ (Fig. 13a). The absence of any cor- 
relation between these ratios demonstrates two different sources for both mobile elements and thus two distinct fluids (EVF- and SR-fluids). CKD-fluid (U-rich) is not significantly enriched in $\mathrm{B}$ and $\mathrm{Li}$, but overlaps with EVFand SR-fluids.

Because the influence of a B-rich fluid decreases from the front to back arc (Fig. 13b; Ryan et al. 1995; Wörner et al. 2001; Ishikawa et al. 2001) and the role of a Li-rich fluid increases, the $\mathrm{Li} / \mathrm{B}$ ratio shows a strong cross-arc zonation (Fig. 13c).

A mass balance for volatile components from slab and mantle wedge

To quantify the changes in fluid composition across the Kamchatka arc, we calculate the relative contribution of volatiles from the mantle wedge and subduction components in a simple batch melting approach. First, we define the compositions of the endmembers. From low HREE concentrations (by a factor $1 / 2$ below N-MORB, Fig. 6) the mantle wedge below Northern Kamchatka is depleted compared to MORB-source (here "KDM': Kamchatka depleted mantle) and only about $5 \%$ of OIB component is added to the mantle sources of the SR magmas.
For volatile elements we choose a conservative approach to define the minimum contribution for the slab fluid to the mantle source:

Sulfur is more compatible in mantle rocks than $\mathrm{Cl}$ and $\mathrm{F}$ and has an enrichment factor of 4 in melts relative to its source (McDonough and Sun 1995). Sulfur abundances for MORB and OIB basalts are similar (800-1,200 ppm, e.g., Wallace and Carmichael 1994; Hauri 2002). Therefore not much initial variation in sulfur concentrations should exist in the Kamchatka mantle wedge prior to fluid enrichment. From these data, 200-300 ppm sulfur has been estimated in MORB and OIB mantle sources (e.g. O'Neill 1991). This range of values is used in our model for the OIB source in the back arc. However, the Kamchatka EVF and CKD sources are depleted compared to MORB-basalts, suggesting also depletion of sulfur in these mantle sources. Lower values of about 50-150 ppm have been reported from fertile peridotites (e.g., McDonough 1990; Hartmann and Wedepohl 1990). Alt et al. (1993) showed that melts produced in a subduction setting from a source depleted relative to MORB-source should have 300-600 ppm of sulfur, suggesting also about 75-150 ppm $S$ in the source. According to these data we assume in our calculations a value of 50-150 ppm S for KDM. Following McDonough
Fig. 13 B-Li-Be systematics across the Kamchatka arc. Our data provide clear evidence for decoupling of B and Li. This results in high $\mathrm{B} / \mathrm{La}(\mathbf{a}, \mathbf{b})$ and $\mathrm{B} / \mathrm{Nb}$ values in arc front magmas and a strong increase in $\mathrm{Li} / \mathrm{Yb}(\mathbf{a}), \mathrm{Li} / \mathrm{B}(\mathbf{c})$ and $\mathrm{Be} / \mathrm{B}$ ratios towards the back arc. Symbols as in Fig. 2
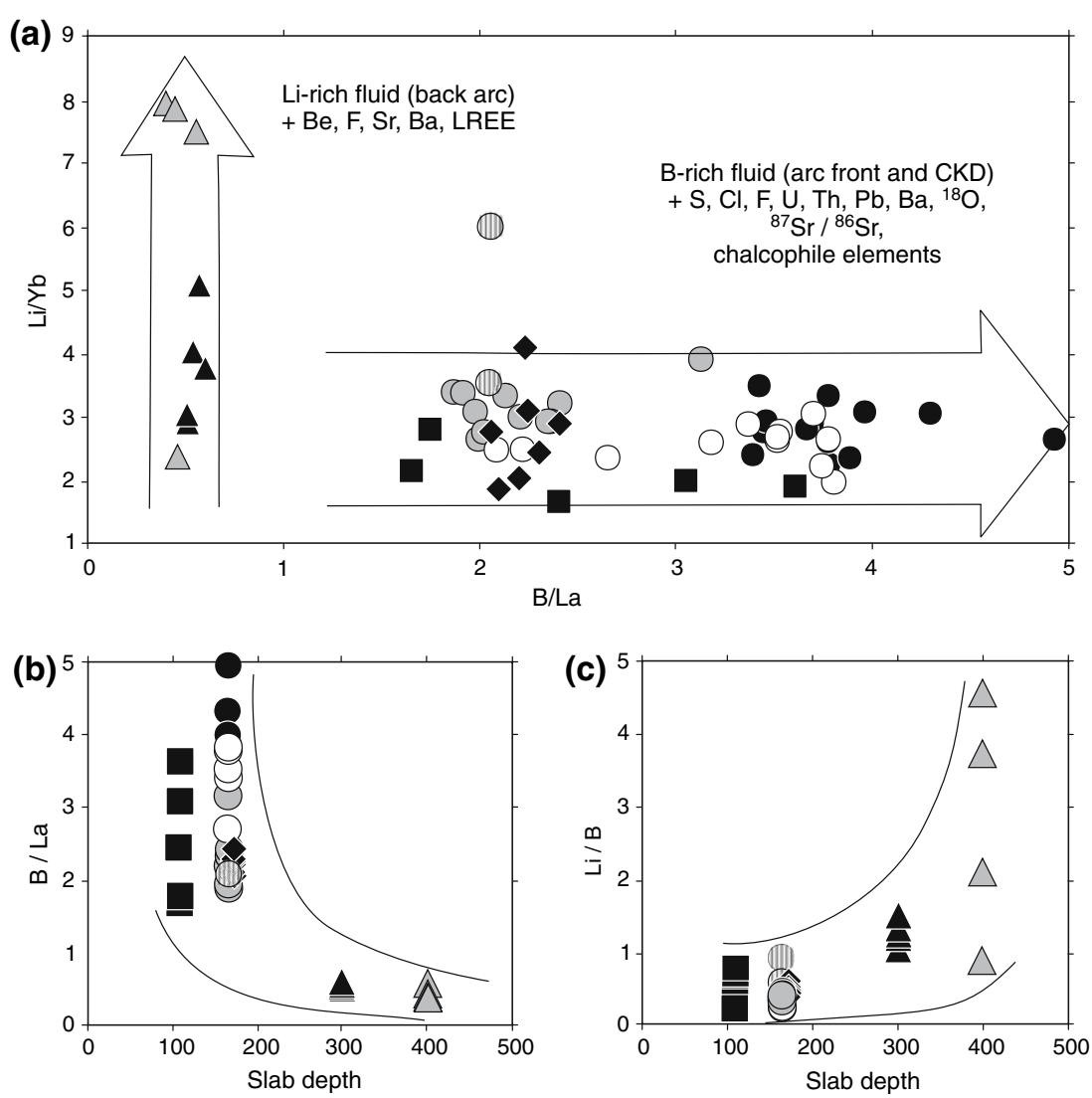
and Sun (1995), a bulk partition coefficient of 0.25 is used for $\mathrm{S}$ in our model.

Chlorine determinations in MORB samples are complicated by sea water assimilation. Using a $\mathrm{Cl} / \mathrm{K}$ ratio in the depleted mantle of 0.19 (Jambon et al. 1995) and potassium values of 60-100 ppm (McDonough et al. 1992; McCulloch and Bennett 1994), $\mathrm{Cl}$ concentrations in depleted mantle should range from 11 to $21 \mathrm{ppm}$. These data are comparable with estimates of Unni and Schilling (1978) for Iceland depleted mantle sources. Nevertheless, Jagoutz et al. (1979) reported a value of only $1.33 \mathrm{ppm}$ in highly depleted ultramafic nodules. We assume the conservative highest value of $21 \mathrm{ppm}$ chlorine in or model for KDM. As for sulfur, a lower mantle contribution for $\mathrm{Cl}$ would result in an even larger amount of $\mathrm{Cl}$ from the slab fluid.

Chlorine in enriched sources varies from $32 \mathrm{ppm}$ in high$\mathrm{K}$ peridotites from continental basalts (Hartmann and Wedepohl 1990) to $61 \mathrm{ppm}$ in rocks from the Iceland ridge (Unni and Schilling 1978). A recent study on melt inclusions in Hawaiian lavas (Hauri 2002) showed that primary melts have 30-300 ppm of chlorine. Using perfect incompatibility and a degree of melting of $25 \%$, a source composition would have 7.5-75 ppm $\mathrm{Cl}$, which is comparable with the above estimates. Taking into account that the lower values could be affected by $\mathrm{Cl}$ degassing from the melts, we use a conservative value of $30-75 \mathrm{ppm} \mathrm{Cl}$ in the OIB source.

Chlorine is a highly incompatible element similar to $\mathrm{Rb}$, Ba, and La (McDonough and Sun 1995; Jambon et al. 1995). Bulk partition coefficient for these elements is about 0.01. By analogy, this value is used for $\mathrm{Cl}$ in our model.

Fluorine in ultramafic low-K nodules range from 7 to 31 ppm (e.g. Jagoutz et al. 1979; Hartmann and Wedepohl 1990). The F/Sr ratio is estimated at about 2 in MORB and OIB basalts (Rowe and Schilling 1979) and 0.7 in very fertile peridotites (Jagoutz et al. 1979). Using these ratios and $\mathrm{Sr}$ in depleted mantle from McCulloch and Bennett (1994), the values for $\mathrm{F}$ should range between 11 and $33 \mathrm{ppm}$, which is comparable with estimates of $36 \mathrm{ppm}$ in depleted Iceland mantle (Rowe and Schilling 1979). We calculate our model with a range from 7 to $36 \mathrm{ppm}$ of $\mathrm{F}$ in the depleted mantle source. McDonough et al. (1992) estimate of $25 \mathrm{ppm} \mathrm{F}$ in primitive mantle is within this range.

Based on fluorine data in pillow lavas, Rowe and Schilling (1979) proposed 74 ppm F for enriched mantle below Iceland. In olivine-hosted melt inclusions from Hawaiian OIB, fluorine values in primary magmas have been estimated between 380 and 540 ppm (Hauri 2002). Using these data and a partition coefficient of 0.06 (after Rowe and Schilling 1979) and assuming 25-30\% of partial melting, the values for Hawaiian OIB source would range between 100 and $180 \mathrm{ppm}$. This range of values is used in our model for the OIB source.
Primary volatile contents in magmas

The average contents for $\mathrm{S}, \mathrm{Cl}$ and $\mathrm{F}$ in Gamchen melt inclusions are taken to be representative for the EVF. Due to their differences in volatiles for Kluchevskoy and $\mathrm{Ka}$ men, their averages are calculated separately. Average values in melts from $\mathrm{FO}_{79-81}$ are used as starting values for Kamen. Because sulfur and chlorine have been affected by degassing during fractional crystallization, the average values of the three least fractionated samples of Kluchevskoy volcano and data from most magnesian olivines $\left(\mathrm{Fo}_{85-87}\right)$ of $\mathrm{SR}$ are taken to represent original $\mathrm{S}$ and $\mathrm{Cl}$ in Kluchevskoy and SR magmas, respectively. Despite large relative uncertainties in the values of $\mathrm{S}$ (and less for $\mathrm{Cl}$ ) in our primary magmas, they are still inside the proposed range of sulfur in undifferentiated sub-arc melts (5002,200 ppm, after Fisher and Marty 2005). However, these values for $\mathrm{S}$ and $\mathrm{Cl}$ can be considered as the minimum values due to shallow level degassing.

Fluorine did not degas from the melts but accumulated during fractional crystallization. Fluorine primary magma values for Kluchevskoy volcano are estimated from the glass inclusions in the most magnesian olivine hosts $\left(\mathrm{Fo}_{89}\right.$ 92) only as $300 \mathrm{ppm}$. F from mafic melt inclusions hosted in most magnesian olivines (Fo $\left.{ }_{85-86}\right)$ from Achtang volcano is taken as the parental value in SR magmas.

\section{Model results}

Based on our estimates for volatile element concentrations and primary volatile contents in magmas, our model compares model melts of unmodified mantle source with observed primary values. Model melts are obtained for 20, 12 and $10 \%$ partial melting for EVF, CKD and SR melts, respectively (Churikova et al. 2001). The difference is quantified and represents the volatile composition from the slab fluid. The modeling results are presented in Fig. 14 as proportion of volatile elements as from the slab fluid versus mantle wedge.

This proportion of volatiles derived from the slab relative to the mantle wedge ("slab/mantle contribution"') and volatile content in melts is well expressed for $\mathrm{S}, \mathrm{Cl}$ and F/ $\mathrm{Cl}$. Fluorine in EVF and CKD samples shows a positive correlation only. A higher fluorine mantle contribution in the source of back arc lavas is due to the OIB component (Fig. 14a-d). Slab contributions relative to mantle gradually decrease from the arc front to the back arc for $\mathrm{S}$ and $\mathrm{Cl}$, but no systematically change is observed for F. The SRfluid is more than five times richer in $\mathrm{F}$ relative to $\mathrm{Cl}$ compared to the arc front fluids (Fig. 14e-h).

From our calculations, more than $60 \%$ of the sulfur and chlorine in Kamchatka melts are contributed from the subducted slab. The same is valid for fluorine in most of 
Fig. 14 Results of the model calculation showing how the contribution from the subducted slab controls the volatile concentrations in the melts (a-d). Slab/mantle contribution represents the contribution of a volatile element from slab fluid relative to the mantle wedge. The slab contribution for $\mathrm{S}$ and $\mathrm{Cl}$ decreases from arc front to back arc (e-f) while $\mathrm{F} / \mathrm{Cl}$ increases (h). The slab/mantle ratio for fluorine does not show a systematic zonation (f). Gray and open fields correspond to the lowest and highest volatile concentrations in the mantle wedge assumed in our model, respectively. Squares EVF, circles Kluchevskoy volcano, diamonds Kamen volcano, triangles SR
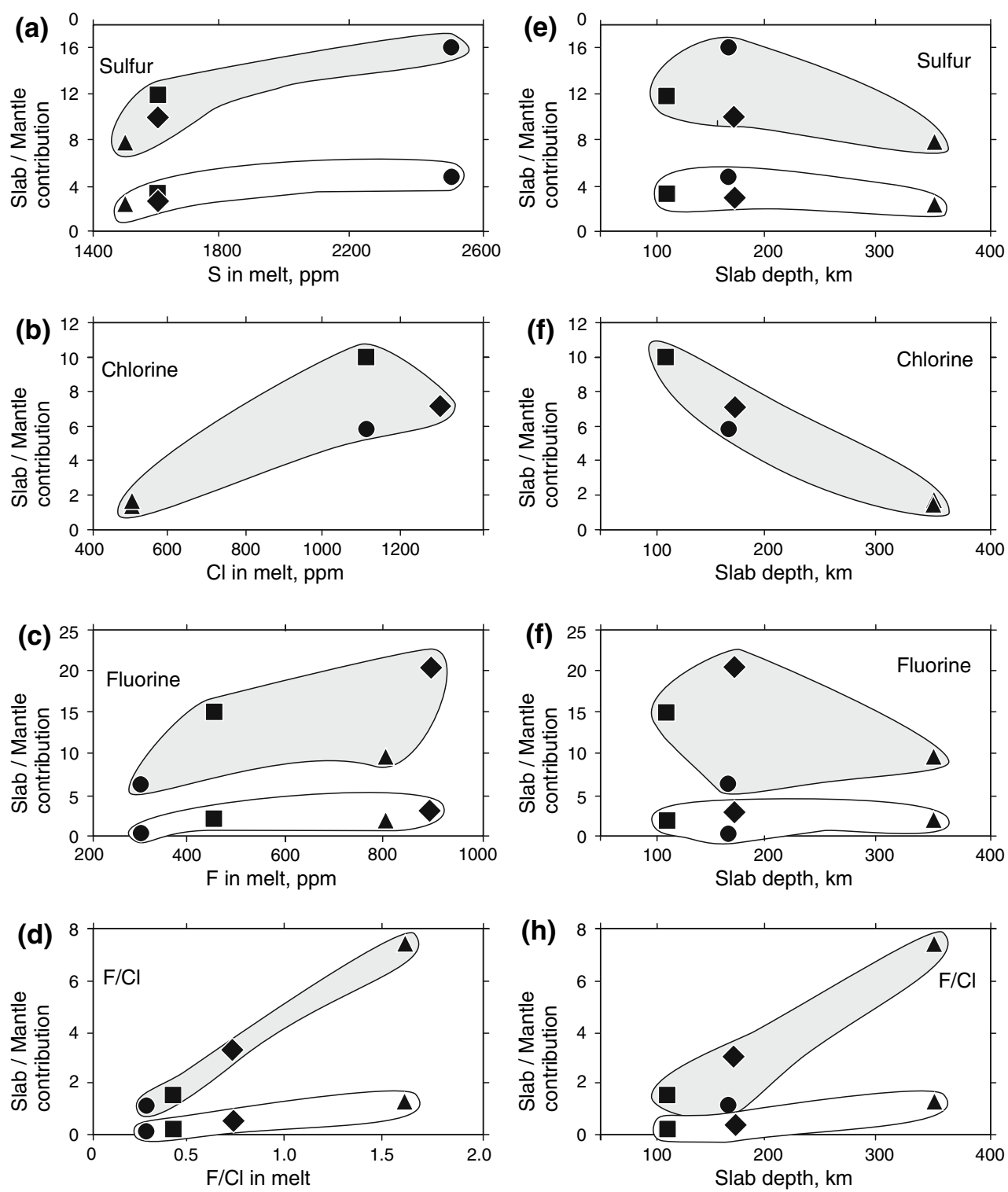

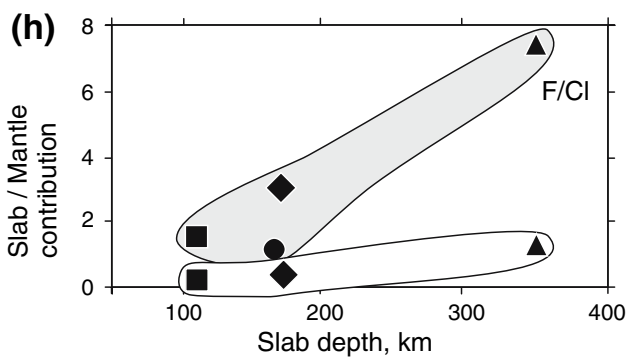

our melts. If we assume the highest plausible $\mathrm{F}$ values for $\mathrm{KDM}$ and OIB (36 and $180 \mathrm{ppm}$ ) then about $30 \%$ of fluorine is contributed from the mantle wedge in Kluchevskoy melts and still about 50\% in the back arc glasses (Fig. 14; Table 4). Thus, a significant amount of volatiles (up to $50 \%$ for fluorine) could be contributed by OIB components in back arc lavas.

The results illustrate that:

(a) Based on the conservative parameters chosen for the model, $\mathrm{Cl}$ and $\mathrm{S}$ are largely contributed $(>60 \%)$ by the slab fluid. A significant portion of $\mathrm{F}$ must also be derived from the slab even for the back arc magmas $(>30-50 \%)$.

(b) The composition of fluids from the subduction component is distinctly different between the three volcanic zones (Table 4): sulfur slightly decreases from the arc front to back arc, but maximum $S$ values (almost twice as high compared to EVF and SR) are observed in Kluchevskoy melts. Chlorine is rather similar in EVF and CKD fluids, but three times lower in SR. Fluorine in EVF and Kluchevskoy is half than that in Kamen and SR fluids (despite an additional contribution from OIB-source in SR);

(c) $\mathrm{Cl} / \mathrm{S}$ ratios in subduction components are two to threefold higher in EVF and Kamen compared to Kluchevskoy (because of its high S content) and SR;

(d) $\mathrm{F} / \mathrm{Cl}$ ratios in fluids increase progressively from East to West across the arc;

(e) This general zonation in fluid composition from arc front to back arc (decrease in $\mathrm{S}$ and $\mathrm{Cl}$ and increase in $\mathrm{F}$ and $\mathrm{F} / \mathrm{Ce}$ ratio) is repeated by significant variations on a smaller local scale: Kluchevskoy and Kamen 
Table 4 Parameters and results of model calculations of the $\mathrm{S}, \mathrm{Cl}$, and $\mathrm{F}$ budget for the mantle wedge and subduction component across the Kamchatka arc

\begin{tabular}{|c|c|c|c|c|c|c|c|c|}
\hline & $\mathrm{S}(\mathrm{ppm})$ & $\%$ & $\mathrm{Cl}(\mathrm{ppm})$ & $\%$ & $\mathrm{~F}(\mathrm{ppm})$ & $\%$ & $\mathrm{Cl} / \mathrm{S}$ in fluid & $\mathrm{F} / \mathrm{Cl}$ in fluid \\
\hline \multicolumn{9}{|l|}{ Melt inclusion data } \\
\hline $\mathrm{EVF}$ & 1,600 & & 1,100 & & 450 & & & \\
\hline Kluchevskoy. CKD & 2,500 & & 1,100 & & 300 & & & \\
\hline Kamen. CKD & 1,600 & & 1,300 & & 900 & & & \\
\hline SR & 1,500 & & 500 & & 600 & & & \\
\hline \multicolumn{9}{|l|}{ Mantle sources } \\
\hline Depleted N-MORB-source & $50-150^{\mathrm{a}}$ & & 21 & & $7-36$ & & & \\
\hline OIB-source & $200-300$ & & $30-75$ & & $100-180$ & & & \\
\hline \multicolumn{9}{|l|}{ Mantle contribution } \\
\hline EVF & $125-375$ & $8-23$ & 101 & 9 & $28-145$ & $6-32$ & & \\
\hline Kluchevskoy. CKD & $147-440$ & $6-18$ & 163 & 15 & $40-208$ & $13-69$ & & \\
\hline Kamen. CKD & $147-440$ & $9-28$ & 163 & 13 & $40-208$ & $4-23$ & & \\
\hline SR & $177-485$ & $12-32$ & $197-217$ & $39-43$ & $76-281$ & $13-47$ & & \\
\hline \multicolumn{9}{|l|}{ Subduction contribution } \\
\hline $\mathrm{EVF}$ & $1,225-1,475$ & $77-92$ & 999 & 91 & $305-422$ & $68-94$ & $0.68-0.82$ & $0.31-0.42$ \\
\hline Kluchevskoy. CKD & $2,060-2,353$ & $82-94$ & 937 & 85 & $92-260$ & $31-87$ & $0.40-0.46$ & $0.10-0.28$ \\
\hline Kamen. CKD & $1,160-1,453$ & $72-91$ & 1,137 & 87 & $692-860$ & $77-96$ & $0.78-0.98$ & $0.61-0.76$ \\
\hline SR & $1,015-1,323$ & $68-78$ & $283-303$ & $57-61$ & $319-524$ & $53-87$ & $0.21-0.30$ & $1.05-1.85$ \\
\hline
\end{tabular}

${ }^{a}$ Ranges in value correspond to the lowest and highest volatile concentrations in the mantle wedge assumed in our model

volcanoes, situated close to each other (about $5 \mathrm{~km}$ ), show a contribution of three significantly different fluids. While the Kluchevskoy source is affected only by EVF- and CKD-fluids, which carry high $\mathrm{S}$ and $\mathrm{Cl}$ but less amounts of F, the source of Kamen lavas has an additional component of the SR-fluid, suggesting an additional $\mathrm{F}$ enrichment from the slab.

\section{Summary and conclusions}

Our data show across-arc variations in volatile and fluid mobile elements in Kamchatka's magmas. Three distinct fluids are identified based on variable volatile elements (S, $\mathrm{Cl}$ and $\mathrm{F}$ ) in the subduction component, which differ significantly across the arc.

The EVF arc front fluid carries the highest amounts of B and $\mathrm{Cl}$. It is also enriched in chalcophile elements, LILE and LREE. The CKD-fluid is highly enriched in $\mathrm{S}$ and $\mathrm{U}$, but less in F. This fluid shows the highest ${ }^{87} \mathrm{Sr} /{ }^{86} \mathrm{Sr},{ }^{18} \mathrm{O}$, ${ }^{11} \mathrm{~B}$ and U/Th signatures, which are attributed to the high fluid flux from the altered subducted oceanic crust and subducted seamounts. The SR-fluid is $\mathrm{Li}$ - and F-rich and is first observed to contribute to the CKD at $180 \mathrm{~km}$ above the slab. In the back arc region (300-400 km above the slab) this fluid carries more $\mathrm{Sr}, \mathrm{Ba}, \mathrm{Be}$ and LREE. In contrast to the neighboring Kluchevskoy volcano (5 km to $\mathrm{N})$, Kamen melts are additionally enriched in phosphorus, lithium and fluorine (Figs. 7a, 11b). Such difference could be explained by deeper melting region compared to Kluchevskoy volcano. As a result, melts from Kamen volcano show overlap by all fluids having high $\mathrm{B} / \mathrm{La}, \mathrm{U} / \mathrm{Th}$ and Li/ Y (Figs. 10, 11b, 13a).

Because all fluids are rich in $\mathrm{Ba}$, no cross-arc variation in the $\mathrm{Ba} / \mathrm{Zr}$ ratio is observed. $\mathrm{B}$ and $\mathrm{Li}$ behave differently and appear to be decoupled. This is an unexpected result. It appears that the absence of a significant sediment contribution allows to better characterize the character of slab fluids derived from subducted oceanic basalts.

$\mathrm{S}$ contents in melt inclusions may be affected by degassing and should be considered as minimum values. Enrichment of CKD melts in S coupled with highest U/Th, ${ }^{87} \mathrm{Sr} /{ }^{86} \mathrm{Sr},{ }^{18} \mathrm{O}$ and ${ }^{11} \mathrm{~B}$ results from a particularly high fluid flux from the altered oceanic crust and subducted seamounts. The strongest slab signature is associated with the highest magma production rate in this region.

$\mathrm{Cl}$ degasses to a lesser extent compared to sulfur and in some samples did not degas at all. Interaction with a mantle component that has been enriched by a Cl-B-Na-rich fluid from the altered subducted basalts could be the major additional source for $\mathrm{Cl}$ in Kamchatka melts.

F content in our melt inclusions is not affected by degassing and thus should reflect primary values. Progressive enrichment in fluorine from East to West could result from the successive of breakdown of F-bearing minerals (like phengite and lawsonite) with increasing slab 
depth. These minerals are enriched in K, Li, LREE and F and could carry water rich fluids to $300 \mathrm{~km}$ depth (Schmidt 1996).

We argue that the dehydration of different water-rich minerals at different depths from the arc front (low $P-T$ conditions) to back arc (high $P-T$ conditions) mainly explains the difference in fluid composition across the Kamchatka arc. Fluids in the arc front are derived from the amphibole and serpentine dehydration and are water-rich, low in silica and high in B, LILE, sulfur and chlorine. These fluids also carry some amount of fluorine but the fluid $\mathrm{F} / \mathrm{Cl}$ ratio is less than 0.5. Bureau and Keppler (1999) showed that such water-rich fluids from the first dehydration slab stage, would be very mobile and should produce large degrees of melting. This is observed in the EVF and CKD.

Fluids released at high pressures below the SR back arc are very different from water-rich arc-front fluids (EVF and CKD) in their density, composition, and mobility. Such deep fluids are much denser. They dissolve significant amounts of silicate minerals (Stalder et al. 2001) and could be highly enriched in LILE and LREE (Keppler 1996).

The CKD appears to be a place where several fluids occur together, suggesting a large heterogeneity in the fluid-modified mantle. This is implied by the fact that Kluchevskoy and Kamen volcanoes, which are situated nearby each other and have rather similar mantle derived components, show quite different fluid patterns. On one hand, a B-rich fluid could be transported to this depth with cold subducted slab and hydrated fore arc mantle. As a result, all melts from the $\mathrm{CKD}$ are enriched in $\mathrm{B}, \mathrm{S}$ and $\mathrm{Cl}$ compared to SR. On the other hand, at a depth between 100 and $200 \mathrm{~km}$, the dehydration of lawsonite and phengite starts and released fluids are poorer in water, but richer in silica and fluorine. Such fluids probably also transport significant amounts of HFSE. Moreover, at this depth, serpentine decomposes to clinohumite, enstatite and fluid (Stalder and Ulmer 2001). Fluids at this depth are less mobile, producing smaller degrees of melting than in the EVF. However, the dehydration of different minerals in oceanic basalts and oceanic lithosphere coupled with active mantle upwelling in CKD region produce a strong fluid flux and high volcanic activity.

A combination of (1) the absence of a significant sediment contribution or crustal assimilation in Kamchatka, (2) the presence of a wide across-arc active volcanic zone with abundant mafic olivine-rich rocks, and (3) the large and variable fluid fluxes expected where large seamounts are being subducted allows us to identify in detail the variations in volatiles and fluid-mobile trace elements with increasing slab depth to $300-400 \mathrm{~km}$. As such, the Kamchatka traverse provides an ideal case for deciphering different fluid signatures. The observed strong geochemical zonations in volatiles and fluid-mobile elements and decoupling of two fluids, one B- and the other Li-rich along the $200 \mathrm{~km}$ transect, can only be explained by continuous dehydration of different water-rich minerals of a single subducted oceanic crust. The significant change in fluid chemistry with slab depth and the overlap of different distinct fluids could provide clues on the type and composition of hydrous phases in the subducting slab.

Acknowledgments E. Nakamura, N. Metrich, A. Gurenko, and T.H. Hansteen are thanked for their detailed and constructive comments on an earlier version of this manuscript. We are grateful to Sergey Simakin who provided us with ion probe analyses and Maxim Portnyagin for samples and discussions. This work was supported by DFG-project Wo362/15-1 + 2 to G.W, by grant No. 00-0504000 from the DFG-RFBR cooperation Program to T.C. and G.W., by grant No. 06-0564873-a from RFBR to N.M. and by grant No. 43.700 .11 .0005 from RF Ministry of Natural Resources.

\section{Reference}

Alt JC, Shanks WC, Jackson MC (1993) Cycling of sulfur in subduction zones; the geochemistry of sulfur in the Mariana island arc and back-arc trough. Earth Planet Sci Lett 119:477-494

Bottazzi P, Ottolini L, Vannucci R, Zanetti A (1994) An accurate procedure for the quantification of rare earth elements in silicates. In: SIMS 9th proceedings. Wiley, New York, pp 927-930

Brenan JM, Neroda E, Lundstrom CC, Shaw HF, Ryerson FJ, Phinney DL (1998a) Behaviour of boron, beryllium, and lithium during melting and crystallization; constraints from mineral-melt partitioning experiments. Geochim Cosmochim Acta 62:2129-2141

Brenan JM, Ryerson FJ, Shaw HF (1998b) The role of aqueous fluids in the slab-to-mantle transfer of boron, beryllium, and lithium during subduction; experiments and models. Geochim Cosmochim Acta 62:3337-3347

Bureau H, Keppler H (1999) Complete miscibility between silicate melts and hydrous fluids in the upper mantle; experimental evidence and geochemical implications. Earth Planet Sci Lett 165:187-196

Bureau H, Keppler H, Metrich N (2000) Volcanic degassing of bromine and iodine; experimental fluid/melt partitioning data and applications to stratospheric chemistry. Earth Planet Sci Lett 183:51-60

Carroll MR,Webster JD (1994) Solubilities of sulfur, noble gases, nitrogen, chlorine, and fluorine in magmas. In: Carroll MR, Holloway JR (eds) Volatiles in magmas. Rev Miner 30, Min Soc Am, Washington DC, pp 231-279

Carroll MR, Rutherford MJ (1988) Sulfur speciation in hydrous experimental glasses of varying oxidation state: results from measured wavelength shifts of sulfur X-rays. AmMiner 73:845849

Castellana B (1998) Geology, chemostratigraphy, and petrogenesis of the Avachinskiy Volcano, Kamchatka, Russia. PhD Thesis, University of California, Los Angeles, pp. 365

Chan LH, Leeman WP, You CF (1999) Lithium isotopic composition of Central American volcanic arc lavas; implications for modification of subarc mantle by slab-derived fluids. Chem Geol 160:255-280

Churikova T, Dorendorf F, Wörner G (2001) Sources and fluids in the mantle wedge below Kamchatka, evidence from across-arc geochemical variation. J Petrol 42:1567-1593 
Danyushevsky LV, Della-Pasqua FN, Sokolov S (2000) Re-equilibration of melt inclusions trapped by magnesian olivine phenocrysts from subduction-related magmas: petrological implications. Contrib Miner Petrol 138:68-83

Danyushevsky LV, McNeill AW, Sobolev AV (2002) Experimental and petrological studies of melt inclusions in phenocrysts from mantle-derived magmas; an overview of techniques, advantages and complications. Chem Geol 183:5-24

De Moor JM, Fisher TP, Hilton DR, Hauri E, Jaffe LA, Camacho JT (2005) Degassing at Anatahan volcano during the May 2003 eruption: implications from petrology, ash leachates, and $\mathrm{SO}_{2}$ emission. J Volcanol Geotherm Res 146:117-138

Dorendorf F, Wiechert U, Wörner G (2000a) Hydrated sub-arc mantle: a source for Kluchevskoy volcano / Kamchatka. Earth Planet Sci Lett 175:69-86

Dorendorf F, Churikova T, Koloskov A, Wörner G (2000b) Late Pleistocene to Holocene activity at Bakening volcano and surrounding monogenetic centers (Kamchatka): volcanic geology and geochemical evolution. J Volcanol Geotherm Res 104:131-151

Edmonds M, Pyle D, Oppenheimer C (2001) A model for degassing at the Soufriere Hills Volcano, Montserrat, West Indies, based on geochemical data. Earth Planet Sci Lett 186:159-173

Fisher TP, Marty B (2005) Volatile abundances in the sub-arc mantle: insights from volcanic and hydrothermal gas discharges. J Volcanol Geotherm Res 140:205-216

Ford CE, Russell DG, Craven JA, Fisk MR (1983) Olivine-liquid equilibria; temperature, pressure and composition dependence of the crystal/liquid cation partition coefficients for $\mathrm{Mg}, \mathrm{Fe}^{(2+)}, \mathrm{Ca}$ and Mn. J Petrol 24:256-265

Geist EL, Scholl DW (1994) Large-scale deformation related to the collision of the Aleutian Arc with Kamchatka. Tectonics 13:538-560

Gerya TV, Yuen DA (2003) Rayleigh-Taylor instabilities from hydration and melting propel 'cold plumes' at subduction zones. Earth Planet Sci Lett 212:47-62

Gorbatov A, Kostoglodov V, Suarez G, Gordeev E (1997) Seismicity and structure of the Kamchatka subduction zone. J Geophys Res B 102(8):17,883-17,898

Hansteen TH, Gurenko A (1998) Sulfur, chlorine, and fluorine in glass inclusions in olivine and clinopyroxene from basaltic hyaloclastites representing the Gran Canaria shield stage at Sites 953 and 956. Proc Ocean Drill Prog Sci Res 157:403-410

Hauri EH (2002) SIMS analysis of volatiles in silicate glasses: 2, isotopes and abundances in Hawaiian melt inclusions. Chem Geol 183:115-141

Hartmann G, Wedepohl KH (1990) Metasomatically altered peridotite xenoliths from the Hessian Depression (Northwest Germany). Geochim Cosmochim Acta 54:71-86

Höflich BLW, Weinbruch S, Ortner HM (2004) Speciation of sulfur in individual aerosol particles from work places by wavelengthdispersive electron-probe microanalysis. Anal Bioanal Chem 378: $167-170$

Ishikawa T, Tera F (1997) Source, composition and distribution of the fluid in the Kurile mantle wedge; constraints from across-arc variations of $\mathrm{B} / \mathrm{Nb}$ and $\mathrm{B}$ isotopes. Earth Planet Sci Lett 152:123-138

Ishikawa T, Tera F, Nakazawa T (2001) Boron isotope and trace element systematics of the three volcanic zones in the Kamchatka arc. Geochim Cosmochim Acta 65:4523-4537

Jagoutz E, Palme H, Baddenhausen H, Blum K, Cendales M, Dreibus G, Spettel B, Lorenz V, Wänke H (1979) The abundances of major, minor and trace elements in the Earth's mantle as derived from primitive ultramafic nodules. In: Merrill, RB, Bogard, DD, Hoerz F, McKay DS, Robertson PC (eds) Proceedings of 10th Lunar Science Conference, pp 2031-2050
Jambon A, Deruelle B, Dreibus G, Pineau F (1995) Chlorine and bromine abundance in MORB; the contrasting behaviour of the Mid-Atlantic Ridge and East Pacific Rise and implications for chlorine geodynamic cycle. Chem Geol 126:101-117

Jarosewich EJ, Nelen JA, Norberg JA (1980) Reference samples for electron microprobe analysis. Geostand Newslett 4:43-47

Jochum KP, Dingwell DB, Hofmann AW, Stoll B, Raczek I, Rocholl A, Becker S, Besmehn A, Besette D, Dietze H -J, Dulski P, Erzinger J, Hellebrand E, Hoppe P, Horn I, Janssens K, Jenner G, Klein M, McDonough WM, Maetz M, Nikogosian IK, Pickhardt C, Seufert H -M, Simakin SG, Sobolev AV, Spettel B, Straub S, Vincze L, Wallianos A, Weckwerth G, Wolf D, Zimmer M (2000) New geological standard reference glasses for in-situ microanalysis. Geostand Newslett 43:55

Keppler H (1996) Constrains from partitioning experiments on the composition of subduction-zone fluids. Nature 380:237-240

Kersting $\mathrm{AB}$, Arculus $\mathrm{RJ}$ (1995) $\mathrm{Pb}$ isotope composition of Klyuchevskoy Volcano, Kamchatka and North Pacific sediments; implications for magma genesis and crustal recycling in the Kamchatkan arc. Earth Planet Sci Lett 136:133-148

Lassiter JC, Hauri EH, Nikogosian IK, Barsczus HG (2002) Chlorinepotassium variations in melt inclusions from Raivavae and Rapa, Austral Islands; constraints on chlorine recycling in the mantle and evidence for brine-induced melting of oceanic crust. Earth Planet Sci Lett 202:525-540

Matthews SJ, Moncrieff DHS, Carroll MR (1999) Empirical calibration of the sulphur valence oxygen barometer from natural and experimental glasses: method and applications. Min Mag 63:421-431

McCulloch MT, Bennett VC (1994) Progressive growth of the Earth's continental crust and depleted mantle; geochemical constraints. Geochim Cosmochim Acta 58:4717-4738

McDonough WF (1990) Constraints on the composition of the continental lithospheric mantle. Earth Planet Sci Lett 101:1-18

McDonough WF, Sun SS (1995) The composition of the Earth. Chem Geol 120:223-253

McDonough WF, Sun S-S, Ringwood AE, Jagoutz E, Hofmann AW (1992) Potassium, rubidium and cesium in the Earth and Moon and the evolution of the mantle of the Earth. Geochim Cosmochim Acta 56:1001-1012

Metrich N, Clocchiatti R (1996) Sulfur abundance and its speciation in oxidized alkaline melts. Geochim Cosmochim Acta 60:41514160

Metrich N, Schiano P, Clocchiatti R, Maury RC (1999) Transfer of sulfur in subduction settings; an example from Batan Island (Luzon volcanic arc, Philippines). Earth Planet Sci Lett 167:114

Moriguti T, Nakamura E (1998) Across-arc variation of Li isotopes in lavas and implications for crust/mantle recycling at subduction zones. Earth Planet Sci Lett 163:167-174

Mosbah M, Metrich N, Massiot P (1991) PIGME fluorine determination using a nuclear microprobe with application to glass inclusions. Nucl Instrum Methods Phys Res B58:227-231

Münker C, Wörner G Yogodzinski G, Churikova T (2004) Behaviour of high field strength elements in subduction zones: constraints from Kamchatka-Aleutian arc lavas. Earth Planet Sci Lett 224:275-293

Nilsson K, Peach CL (1993) Sulfur speciation, oxidation state and sulfur concentration in back-arc magmas. Geochim Cosmochim Acta 57:3807-3813

Nosova AA, Sazonova LV, Narkisova VV, Simakin SG (2002) Minor elements in clinopyroxene from Paleozoic volcanics of the Tagil island arc in the Central Urals. Geochemistry 3:254-268

O'Neill HStC (1991) The origin of the Moon and the early history of the Earth; a chemical model; part 2, The Earth. Geochim Cosmochim Acta 55:1159-1172 
Portnyagin MV, Simakin SG, Sobolev AV (2002) Fluorine in primitive magmas of the Troodos Ophiolite complex, Cyprus: analytical methods and main results. Geochem Int 40:625-632

Rowe EC, Schilling JG (1979) Fluorine in Iceland and Reykjanes Ridge basalts. Nature 279:33-37

Ryan JG, Langmuir CH (1987) The systematics of lithium abundances in young volcanic rocks. Geochim Cosmochim Acta $51: 1727-1741$

Ryan JG, Morris J, Tera F, Leeman WP, Tsvetkov A (1995) Cross-arc geochemical variations in the Kurile Arc as a function of slab depth. Science 270:625-627

Schmidt MW (1996) Experimental constraints on recycling of potassium from subducted oceanic crust. Science 272:1927-1930

Smirnov VK, Sobolev AV, Batanova VG, Portnyagin MV, Simakin SG, Potapov EV (1995) Quantitative SIMS analysis of melt inclusions and host minerals for trace elements and H2O. EOS Trans/Spring Meeting Suppl 76: 17, 270

Sobolev AV, Danyushevsky LV (1994) Petrology and geochemistry of boninites from the north termination of the Tonga Trench; constraints on the generation conditions of primary high-Ca boninite magmas. J Petrol 3:1183-1211

Sobolev AV, Slutsky AB (1984) Composition and crystallization conditions of the initial melt of the Siberian meimechites in relation to the general problem of the ultrabasic magmas. Sov Geol Geophys 25:93-104

Sobolev AV, Hofmann AW, Nikogosian IK (2000) Recycled oceanic crust observed in 'ghost plagioclase' within the source of Mauna Loa lavas. Nature 404:986-990

Stalder R, Ulmer P (2001) Phase relations of a serpentine composition between 5 and $14 \mathrm{GPa}$; significance of clinohumite and phase $\mathrm{E}$ as water carriers into the transition zone. Contrib Miner Petrol 140:670-679
Stalder R, Ulmer P, Thompson AB, Guenther D (2001) High pressure fluids in the system $\mathrm{MgO}-\mathrm{SiO}$ (sub 2) $-\mathrm{H}_{2} \mathrm{O}$ under upper mantle conditions. Contrib Miner Petrol 140:607-618

Sun SS, McDonough WF (1989) Chemical and isotopic systematics of oceanic basalts; implications for mantle composition and processes In: Saunders AD, Norry MJ (eds) Magmatism in the ocean basins. Geol Soc Spec Publ, pp 313-345

Tsvetkov AA, Gladkov NG, Volynets ON (1989) Problem of sediment subduction and ${ }^{10} \mathrm{Be}$ isotope in lavas of Kuril Islands and Kamchatka Peninsula. Trans USSR Acad Sci 306:1220 1225

Turner S, McDermott F, Hawkesworth C, Kepezhinskas P (1998) A U-series study of lavas from Kamchatka and the Aleutians: constraints on source composition and melting processes. Contrib Miner Petrol 133:217-234

Unni CK, Schilling JG (1978) $\mathrm{Cl}$ and $\mathrm{Br}$ degassing by volcanism along the Reykjanes Ridge and Iceland. Nature 272:19-23

Wallace PJ (2005) Volatiles in subduction zone magmas: concentrations and fluxes based on melt inclusion and volcanic gas data. $\mathbf{J}$ Volcanol Geotherm Res 140:217-240

Wallace PJ, Carmichael ISE (1994) S speciation in submarine basaltic glasses as determined by measurements of SKalpha X-ray wavelength shifts. Am Miner 79:161-167

Wörner G, Churikova T, Leeman W, Liebetrau V, Tonarini S, Heuser A (2001) Fluid-mobile trace element and U-series isotope variations across Kamchatka: timing and effects of slab dehydration margins meeting. Schriftenreihe D Geol Ges 14:236-237

Yogodzinski GM, Lees JM, Churikova TG, Dorendorf F, Wörner G, Volynets ON (2001) Geochemical evidence for the melting of subducting oceanic lithosphere at plate edges. Nature 409:500 504 